\title{
ESTUDO DA UTILIZAÇÃO DE SOLOS LATERÍTICOS E A METODOLOGIA MCT: ANÁLISE EM TRECHO A SER DUPLICADO NA BR-116
}

\section{ARTIGO ORIGINAL}

PEREIRA, Lázaro Fernandes ${ }^{1}$

SILVA, Amanda Lima da ${ }^{2}$

CORREIA, Bianca Maria Oliveira Prado ${ }^{3}$

GUIMARÃES, Eduardo Melo ${ }^{4}$

MINEIRO, Gardênia Olimpia ${ }^{5}$

OLIVEIRA, Marcelo Alves de Alencar Sena ${ }^{6}$

${ }^{1}$ Graduado em Ciências Contábeis pela Universidade Norte do Paraná-UNOPAR (2014), Pós-graduado Latu Senso (MBA) em Gerenciamento de Obras de Engenharia pela UniFG (UniGrad - 2019), Bacharelando em Engenharia Civil pela Faculdade Independente do Nordeste - FAINOR.

${ }^{2}$ Bacharelanda em Engenharia Civil pela Faculdade Independente do Nordeste FAINOR.

${ }^{3}$ Bacharelanda em Engenharia Civil pela Faculdade Independente do Nordeste FAINOR.

${ }^{4}$ Bacharelando em Engenharia Civil pela Faculdade Independente do Nordeste FAINOR.

${ }^{5}$ Bacharelanda em Engenharia Civil pela Faculdade Independente do Nordeste FAINOR.

${ }^{6}$ Bacharelando em Engenharia Civil pela Faculdade Independente do Nordeste FAINOR. 
LIMA, Lívia Ramos ${ }^{7}$

PEREIRA, Lázaro Fernandes. Et al. Estudo da utilização de solos lateríticos e a metodologia MCT: Análise em trecho a ser duplicado na BR-116. Revista Científica Multidisciplinar Núcleo do Conhecimento. Ano 05, Ed. 06, Vol. 02, pp. 72105. Junho de 2020. ISSN: 2448-0959, Link de acesso: https://www.nucleodoconhecimento.com.br/engenharia-civil/utilizacao-desolos

\section{RESUMO}

O aumento de novas metodologias no campo da engenharia vem se tornando cada vez mais alvo de pesquisas e inovações, principalmente em se tratando de infraestrutura (pavimentação), tanto para o material aplicado quanto a métodos de dimensionamento. O conhecimento das propriedades, características e comportamento dos materiais que são utilizados é de suma importância, pois estão inteiramente ligados com os métodos de dimensionamento e execução de um pavimento. Sabe-se da existência da grande malha rodoviária do país, em extensão ainda não pavimentada segundo dados da Confederação Nacional de Transporte é pouco menos de 13\%em como é grande o número de estradas e rodovias já executadas que não resistem às solicitações que lhes são impostas, ou que apresentam patologias num curto período de uso pelo tráfego. Dada então, a grande relevância de um projeto alinhado a escolha dos métodos executivos e a estabilização entre viabilidade de implantação, eficiência do pavimento e economia em sua execução. Ressalta-se que a utilização de matérias primas que são componentes de camadas do pavimento se torna mais viável economicamente quando há o uso dos recursos naturais já existentes nas proximidades de onde será implantado, evitando movimentações de terra a longas distancias que deixam a obra mais onerosa. A metodologia MCT - Miniatura Compactada Tropical - é o alvo direto de pesquisa e utilização, aplicáveis para pavimento flexível com a utilização de solos lateríticos.

7 Graduação em Enfermagem. Graduação em Engenharia Civil. Especialização em Engenharia Rodoviária: Do Estudo De Viabilidade Ao Projeto Executivo. 
Paralelo aos estudos bibliográficos fez-se o mapeamento prévio dos pontos de coleta, realização de ensaios laboratoriais e a constatação dos parâmetros e análise dos solos lateríticos coletados como apresentados neste trabalho. De fato, constatou-se através do uso da metodologia MCT que o solo da área mapeada em localizações específicas são sim solos lateríticos e corroboram com as análises que deram referências a esse trabalho dos autores e pesquisadores Nogami e Villibor.

Palavras-chave: Pavimentação, solos lateríticos, metodologia MCT.

\section{INTRODUÇÃO}

O pavimento é uma combinação de camadas, estas recebem a repartição das cargas de forma aliviada e criteriosa. Em específica camada superficial (revestimento asfáltico) que é apoiada sobre a camada de base, sub-base e reforço do subleito e são compostas de materiais granulares, solos ou misturas de solos (estabilização) (SILVA, 2015).

Este trabalho é voltado à economia dos pavimentos, segue linha de pesquisa da utilização de solos lateríticos em camadas superiores com o uso da metodologia MCT (Miniatura, Compactada, Tropical) como base de ensaios. A análise será feita em áreas a serem duplicadas na BR-116/BA, mais especificadamente, sob a concessão da VIABAHIA Concessionária de Rodovias S.A.

Existentes em países de clima quente e úmido como o Brasil, esses solos possuem propriedades de comportamento laterítico adquiridos durante seu processo de formação.

O planejamento de novos procedimentos e materiais na construção é dada pela insuficiência de matéria prima e elevação de custos. A utilização de novos produtos industriais que substituam até mesmo os naturais, é um assunto de grande ênfase nos últimos anos, devido a possibilidade de serem resolvidos problemas de caráter ligado à economia, tecnologia e meio ambiente. 
$\mathrm{Na}$ construção civil, em tese no modal rodoviário, o incremento de materiais alternativos, empregando subprodutos industriais, como os estabilizantes por exemplo é de fundamental importância devido a sua capacidade de aplicar esses novos materiais em quantidades elevadas, especialmente em países em desenvolvimento, esse fato é impulsionado pela precisão do aumento das malhas rodoviárias e pela diminuição de custo nos pavimentos.

É se fundamental importância que se use produtos estabilizantes de solo no tratamento de base e sub-base de pavimentação asfáltica, que seja de fácil aplicação e que reduza os custos em remoção, transporte de bota fora e importação de caixas de empréstimo para bases, em obras de rodovias, vias urbanas, pátio de manobras ou estacionamento de veículos pesados, além da ação efetiva no processo de impermeabilização do solo. Sua aplicação introduz novos parâmetros aos solos utilizados devido ao seu efeito aglutinante e estabilizante. Atua nas partículas do solo, dispensando o uso da pedra, do cimento ou de outros agregados utilizados na base convencional. (SILVA, 2015)

O modal rodoviário no Brasil tem evoluído a cada dia e tem sido abrangente as linhas de pesquisas voltadas a esse setor. $O$ foco baseado na eficiência e economia tem aguçado a visão dos pesquisadores buscando atender as demandas de projeto e mercado trazendo cada vez mais inovação. Pensando em rodovias pensa-se logo em execução da pavimentação asfáltica e sua viabilidade econômica. Tem-se como foco nessa pesquisa as camadas superiores base e sub-base da pavimentação com o intuito de torna-las mais econômicas substituindo o material convencionalmente utilizado por Solo Laterítico, usando estabilizantes para que o mesmo atenda às solicitações de cargas características de rodovias de tráfego pesado sendo que a utilização existente está em vias vicinais e urbanas (tráfego intermediário e leve).

A construção de um pavimento demanda domínio do conhecimento não só dos materiais que o compõe, mas de outros produtos, subprodutos e materiais que podem garantir a estabilização do solo, trazendo garantia de suas propriedades, baixa manutenção e custo adequado. Para esse projeto de pesquisa, foram abordados metodologia específica (MCT), tipo específico de solos (Laterítico) e antemão dois 
tipos de estabilização de solos, tendendo auxiliar à concessionária esta escolha, evidenciando qual o tipo de estabilização ela pode optar, com auxílio de parâmetros técnicos, práticos e dados comparativos.

\section{FUNDAMENTAÇÃO TEÓRICA}

\subsection{PEDOLOGIA}

A pedologia é uma ciência com pouco mais de um século por isso considera-se uma ciência recente. Da etimologia da palavra, do grego e europeu, pedon (lugar ou solo onde se pisa, solo) a logos (discurso ou razão, estudo). Descreve-se o solo como: "a massa de elementos agregados, geralmente friáveis, que se encontra na superfície da face emersa da crosta terrestre, resultante das ações da atmosfera e biosfera sobre a litosfera, durante um tempo determinado". Por sua formação, possui distinção de propriedades dos demais elementos da natureza, essas propriedades que os caracterizam é que compõe a parte descritiva e estática da pedologia como estudo.

Os solos são constituídos de quatro elementos físicos e percentualmente avulsos em $45 \%$ minerais, 5\% material orgânico, 25\% água e 25\% ar. Essa composição está em processo mecânico e dinâmico na natureza e faz com que haja diversas interações que são consideradas primordiais no procedimento evolutivo e de constituição dos solos. Pode-se referir a interação do ar do solo com a atmosfera dando condições biológicas do seu interior, de igual forma a água do solo proveniente das chuvas que causa reações e alterações nas rochas dada por processo de percolação com a possibilidade de ir até os lençóis freáticos tornando também parte da hidrosfera, por fim e não menos formidável embora exiba pequeno percentual como elemento temse o material orgânico, responsável pelas ações que dão condições à nutrição do solo e conservação da sua série de nutrientes e ligação com a litosfera fazendo parte da camada externa do solo. (NETO, 1982)

Para isso a importância e fundamento da análise dos solos, em campo e no laboratório, é o que se chama de pedologia descritiva. Há também a pedologia 
dinâmica e que está relacionada aos experimentos e comportamento mecânico dos solos, atingindo seus aspectos usuais a cada finalidade em geral.

É de interesse do pedólogo tanto as camadas presentes na superfície, ou seja, as camadas superiores quanto as camadas internas, ou inferiores, essa análise recebe o nome de Pedogênese. Não se preocupa com a aplicabilidade dos solos ou a finalidade dos mesmos, mais sim com a sua origem, composição, distribuição e o que influenciou para que tenha as características que possuem (LEPCH, 2010).

\subsection{FORMAÇÃO DOS TIPOS E PERFIS DOS SOLOS}

Lima e Lima (2007) tratam a respeito de formação dos solos descrevendo como se resultam ou se formam. Sendo assim, pela influência da rocha de origem, bem como do clima, relevo, tempo e organismo. Durante seu processo de desenvolvimento passa por alguns processos como Perda, Transformação, Adição e Transportes, ambos, responsáveis por todo e qualquer tipo de solo que existe.

Dos fatores de desenvolvimento dos solos, tomando inicialmente o material de origem têm-se os de natureza mineral e orgânica. Ressalta-se que a depender dos minerais é que possuirão na sua formação as características como areia, argila, silte e os chamados solos pobres. Em questão do Clima, é de extrema relevância quanto á formação dos solos, pois as altas ou baixas temperaturas, precipitações, desertificação dentre outros beneficiam no sentido de acelerar ou prejudica no retardar no processo de alteração das rochas. O relevo influencia no dimensionamento ou profundidade dos solos, onde em terrenos planos pela distribuição das águas serem mais uniformes geralmente formam solos mais profundos e em terrenos mais inclinados ocorrem a formação de solos menos espessos até mesmo pelo processo de ocorrência de erosão. Os organismos representam sua fração de contribuição dentre os fatores, pois são encarregados pelo enriquecimento orgânico, as plantas têm influência no sentido de retenção de água ou proteção do contato direto da água da chuva com o solo, evitando erosões por exemplo. E por fim o fator tempo, que embora não se tenha mensurado exatamente quanto que demora para um solo se 
formar, sabe-se que gira por volta de milhares de anos, e depende do clima, relevo e característica da rocha. (LIMA e LIMA, 2007)

Dos processos de formação cita-se o da Adição, dada por meio de materiais orgânicos somados ao solo, o que dá a coloração escura nele presente. Em regiões mais chuvosas, ocorre a presença maior de vegetação e consequentemente de material orgânico também. Quanto ao processo de Perda, dá-se por meio de precipitações, a água percola levando os minerais existentes para as camadas inferiores e há perca de minerais nas camadas superiores pela erosão decorrente da água das chuvas. Ainda sobre o procedimento de formação, cita-se a influência por modificações químicas, físicas e biológicas dos solos.

O intemperismo climático contribui para isso, transformando os minerais existentes na rocha em minerais novos. Os já existentes chamam-se de primários e os transformados de minerais secundários. Essa é denominada de alteração física. Já a alteração química é por meio da liberação de óxido de ferro das rochas, o que atribui à coloração avermelhada, amarelada ou vermelho-amarelada dos solos. Alteração biológica é a ocorrência da transformação por meio dos materiais orgânicos que caem das árvores e derivados de vegetação, ao se decomporem, os humos dão a coloração preta dos solos. Esse processo é um dos mais contribuintes do setor chave que será tomado como matéria prima para o abordado em estudo e pesquisa desenvolvidos, que se correlaciona com a formação dos solos e ainda mais específicos os Solos Lateríticos. (LIMA e LIMA, 2007)

O clima do Brasil, por exemplo, é condizente com a abrangência desse tipo de solo. Bem como, não se faz presente em todo seu território.

As transformações ocorridas durante todos os estágios de desenvolvimento dos solos são mais intensas em regiões úmidas e quentes (zonas tropicais). A água é necessária para hidratar e dissolver minerais, processo que é acelerado em temperaturas mais elevadas. $\mathrm{Na}$ porção tropical úmida do Brasil, ocorrem solos considerados muito velhos e intemperizados por terem sido submetidos durante muito tempo 
a esses processos de transformação e perda, sendo, como resultado, muito profundos e muito pobres em nutrientes. (LIMA e LIMA, 2007)

Por fim e não menos importante o processo de formação do solo por Transportes de materiais orgânicos por meio de gravidade ou evapotranspiração devido ao elevado teor de calor. Há essa ocorrência de transporte tanto das camadas inferiores para as superiores bem como em seu sentido inverso. Através de todos esses processos pedogenéticos (transformações, perdas, transportes e adições) os solos vão se dividindo em camadas ou horizontes, com espessuras e profundidade variadas, cores e granulometrias diferentes, perfis diferenciados pelos variados processos de transformação da rocha mãe.

Conforme Lima e Lima (2007) hipoteticamente, nota-se na Figura 1 a sequência cronológica da formação dos solos. Sinalizados com as letras A, os materiais formados por matéria orgânica, o que dá essa pigmentação mais escura. Já os perfis de pigmentação vermelha e amarelada, sinalizados com a letra $B$, refere-se a presença de oxido de ferro. Em C, as rochas que já apresentam alterações, nota-se as cores vermelha e acinzentada. $E$ em $R$, a chamada rocha sã, pertencentes aos horizontes e camadas que se originam os solos.

Figura 1: Descrição dos horizontes da camada de solo

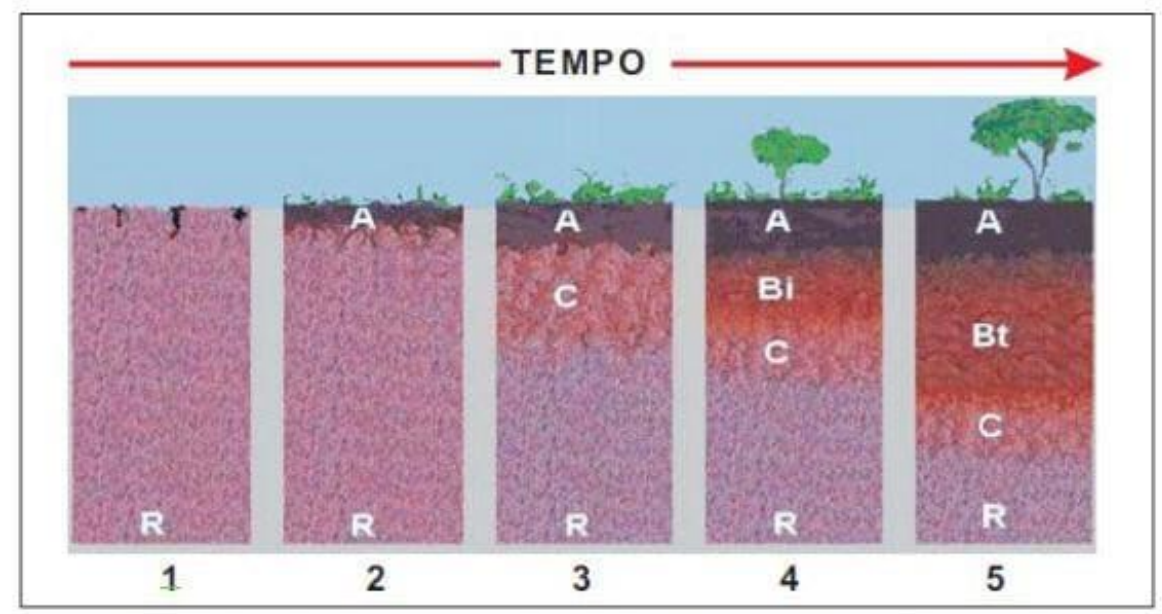

Fonte: Lima e Lima (2007) 


\subsection{ESTRUTURA DE UM PAVIMENTO}

Usualmente essa estrutura se divide em: subleito, reforço do subleito, sub-base, base e revestimento, se tratando do tipo de pavimento abordado que é o flexível:

\subsubsection{SUBLEITO}

O subleito é composto de material natural trabalhado, ou seja, consolidado e compactado. É o terreno de fundação do pavimento, deve ser executado cumprindo todos os requisitos técnicos para que não comprometa o trabalho da pavimentação. Segundo Senço (2007), sabe-se da infinidade relacionada à profundidade do solo, mediante a isso, considera-se subleito apelas a camada mais próxima à superfície, à medida que se adentra no maciço, o que é exercido de pressão no solo é demasiadamente irrisório. Os chamados bulbos de tensões geram curvas apresentando em porcentagem a pressão de contato, no qual a mesma diminui à medida que é aumentada a profundidade.

\subsubsection{REFORÇO DO SUBLEITO}

É uma camada que é construída, quando necessário, acima do subleito já regularizado. Ocorridas geralmente quando encontrado fundações de má qualidade ou quando ocorrerá altas solicitações de cargas, Senço (2007).

\subsubsection{SUB-BASE}

Para o autor antes mencionado, sub-base é a camada que dá complemento a base, quando, as condições econômicas e técnicas não permitirem a execução da base diretamente sobre o subleito regularizado ou o reforçado.

\subsubsection{BASE}

Construída com solo natural e a estabilização pode decorrer da adequada distribuição granulométricas dos grãos, (pedra britada, seixo rolado) ou ser adquirida com 
produtos químicos. Essa camada atua no combate aos esforços verticais que recebe do tráfego e tem a função de distribui-los às camadas inferiores.

\subsubsection{REVESTIMENTO}

Dentre outras funções, o revestimento é encarregado de receber diretamente as cargas estáticas ou dinâmicas, sem sofrer grandes deformações elásticas ou plásticas, desagregação de componentes ou, ainda perda de compactação; carece, portanto, ser conjugado de materiais bem aglutinados ou preparados de maneira a evitar sua movimentação no sentido horizontal. Pode-se analisar, esquematizado abaixo, na Figura 2, a distribuição das camadas de um pavimento:

Figura 2: Distribuição das camadas de um pavimento flexível

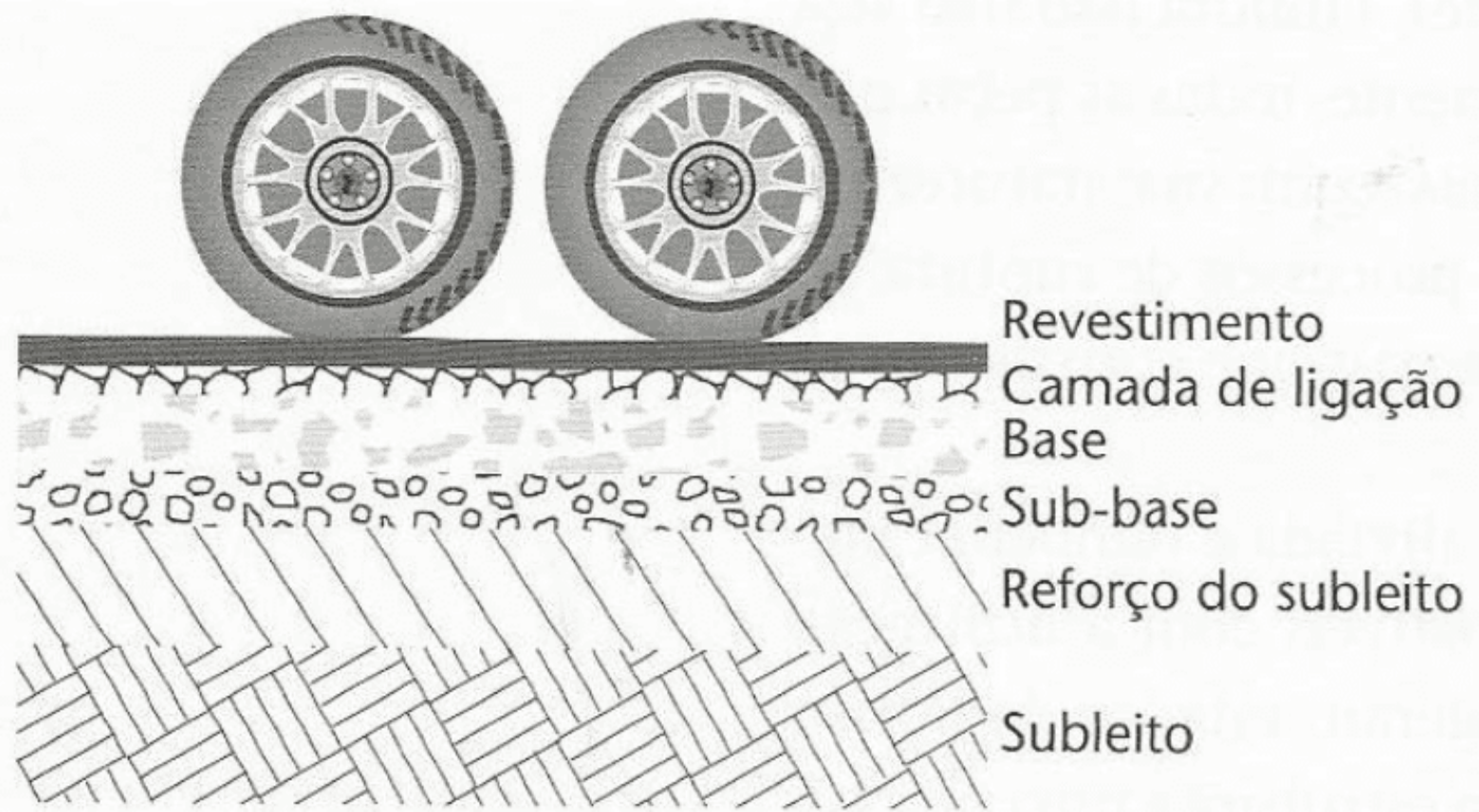

Fonte: Silva (2015)

\subsection{SOLOS LATERÍTICOS NO BRASIL}

A laterita e solos lateríticos no Brasil, são matérias-primas ou o postos-chave principal para análise de estudo e posterior a isso a sua devida aplicação em pavimentação rodoviária. Passando apenas pela nomenclatura ou significado do termo laterita é 
definida como um depósito enrijecidos de resíduos decorrentes de rochas intemperizadas e materiais da superfície ainda em processo de transformação, estão alojados em variados relevos e regiões. Espíndola e Daniel (2008)

De acordo esses mesmos autores, do saber da formação do processo pedogenético dos solos bem como suas condições de ocorrência pode-se classificá-los devido a sua espessura. Solos que possuem camadas acima de 2 metros, indicam a sua boa evolução e também um bom desenvolvimento. Estes, com baixa presença de silte, bases dessaturadas, possuem sua predominância argilosa, o que pode leva-los à associação da presença de oxi-hidróxidos de alumínio, abastados em óxido de ferro e com areia advinda do quartzo que são constituintes de materiais de alta resistência e pesados.

Solos Lateríticos são os associados a laterita, por extensão possuem um alto grau de amadurecimento conforme suas atribuições. Há também a existência destes solos pouco desenvolvidos, rasos. Ocorre que esses são de pouca expressividade em relação aos bem desenvolvidos. O termo Solo Laterítico é mais usado pelos engenheiros em geral envolvidos ao ramo da geotecnia, porém a ciência que estuda os solos, a Pedologia denomina-o como latossolos (NOGAMI e VILLIBOR, 1995).

Este tipo de solo é amplamente encontrado em relevos suaves no Brasil e países de clima tropical úmido, são bastante permeáveis a menos que tenha sofrido algum processo em sua superfície provocado pela ação humana, os taludes por exemplo (em rodovias construídas a um intervalo de tempo considerável). O intemperismo faz com que a presença do óxido de ferro seja manifestada de forma clara, fazendo com que já nesse nível de alteração sua característica de coloração é vermelho-amarelada de aspecto ferruginoso, essa é uma das evidencias de jovialidade dos solos. (ESPÍNDOLA e DANIEL, 2008)

Embora por meio de observação nota-se que o solo não chega ao seu auge evolutivo, essa continuidade na evolução, vai das pequenas alterações ou modificações em sua superfície e causa interferências em suas camadas mais espessas, isso ocorre por meio das depressões fechadas em áreas drenantes o que propicia o rejuvenescimento 
do relevo dos solos em determinadas regiões. Portanto, nem sempre pelo visual podese determinar a antiguidade ou estabilidade dos solos. (ESPÍNDOLA e DANIEL, 2008)

\subsection{METODOLOGIA MCT}

\subsubsection{CLASSIFICAÇÃO MCT}

Os autores e pesquisadores, objetivaram a busca de nos métodos classificatórios e de identificação de solos tropicais, isso fez com que iniciassem com a proposta da sistemática MCT (NOGAMI e VILLIBOR, 1995).

Os ensaios até então utilizados, foram desenvolvidos com base em análise de solos de outros países, portanto, possuem suas características dadas pelo processo de formação diferentes dos solos como os de países de clima tropical. Diante da dificuldade de adaptação a ensaios direcionados ao solo que predomina o país -se dentre outros normativos rodoviários o Ensaio de Mini-CBR e Expansão (DNER-ME 254/97) para fins de avaliação expedita do suporte de solos típicos das regiões tropicais e Mini-MCV (DNER-ME 258/94) onde são determinados coeficientes empíricos utilizados na caracterização de solos tropicais com de corpos de prova de dimensões reduzidas de $50 \mathrm{~mm}$ de diâmetro e $50 \mathrm{~mm}$ de altura.

Nogami e Villibor (1981) classificam os solos em dois grupos, solos laterítico (L) ou não lateríticos (N). E como complemento a isso, Nogami e Villibor (1995), subdividiu sete grupos dentro dessa classificação, essa subdivisão é apresentada no Quadro 1. 
Quadro 1: Subclassificação dos solos lateríticos segundo a metodologia MCT

\begin{tabular}{|c|c|}
\hline SOLOS LATERÍTICOS (L) & SOLOS NÃO LATERÍTICOS (N) \\
\hline $\begin{array}{l}\text { Areias Lateríticas (LA): com a pouca presença de finos } \\
\text { de comportamento laterítico; }\end{array}$ & $\begin{array}{l}\text { Areias não Lateríticas (NA): pouquíssima ou } \\
\text { nenhuma presença dos finos argilosos. } \\
\text { Constituintes de areias e siltes; }\end{array}$ \\
\hline $\begin{array}{l}\text { Solos Arenosos Lateríticos (LA'): são de fato arenosos } \\
\text { em tátil e visualmente falando. Possuem pigmentação } \\
\text { amarela e vermelha, quando expostos às intempéries eles } \\
\text { apresentam com trincas visíveis; }\end{array}$ & $\begin{array}{l}\text { Solos Arenosos não Lateríticos (NA'): em } \\
\text { sua maior composição, há presença de areia de } \\
\text { quartzo, os finos presentes neste, não se } \\
\text { comportam como lateriticos; }\end{array}$ \\
\hline $\begin{array}{l}\text { Solos Argilosos Lateríticos (LG'): constituídos por } \\
\text { argilas e argilas arenosas. Quando há predominância de } \\
\text { areia, eles apresentam as mesmas características do LA'; }\end{array}$ & $\begin{array}{l}\text { Solos Siltosos não Lateríticos (NS'): } \\
\text { derivados das rochas eruptivas e metamórficas, } \\
\text { a partir do intemperismo característico de } \\
\text { climas tropicais; }\end{array}$ \\
\hline & $\begin{array}{l}\text { Argilosos não Lateríticos (NG'): } \\
\text { compreendidos por solos saprolíticos argilosos } \\
\text { de camadas superficiais. }\end{array}$ \\
\hline
\end{tabular}

Fonte: Adaptado pelos autores, Nogami e Villibor (1995).

Para essa metodologia, como meio de classificação, criou-se um ábaco no qual, temse a observação desses solos através de valores de coeficientes c', d' e e'.

\subsubsection{COEFICIENTE c'}

A cada teor de umidade existente, é traçada uma curva com o número de golpes aplicados em função do afundamento de cada corpo de prova. Após traçadas as curvas que indicam o quanto o material se deformou, resultantes da extração dos dados e dos resultados dos ensaios mencionados anteriormente, segue com a determinação do c', obtido pela razão existente entre o quanto variou o afundamento pela variação do Mini-MCV da parte mais assemelhada a uma reta da curva de deformabilidade. 
O coeficiente c' dos solos lateríticos é o indicativo do aspecto granulométrico do material, ou seja, se arenoso ou argiloso. Assim c' com valor acima de 1,5 está ligado aos solos mais argilosos e as argilas em si, quando apresentam valores abaixo de 1,0 correspondem as areias e os siltes não plásticos ou pouco coesivos. Entre 1 a 1,5 estão presentes os solos com diferentes granulometrias, compreendido por areias siltosas, areias argilosas, areia arenosas, argilas siltosas, etc (NOGAMI e VILLIBOR, 1995).

\subsubsection{COEFICIENTE d'}

Como descrito anteriormente. Com alturas do afundamento dos corpos de prova compactados, obtém-se as massas específicas aparentes secas (MEAS) e então para os números de golpes $\mathrm{n}=10$ se traçam as curvas de "MEAS versus $\mathrm{Hc}$ ".

As areias argilosas bem graduadas possuem curvas de compactação com picos acentuados e localização da parte mais reta da curva no ramo seco, cuja inclinação se acentua sutilmente, quando a argila presente é de natureza laterítica. As argilas lateríticas possuem curvas similares, porém com inclinações menores.

Percebe-se, que os solos lateríticos, alcançam alto grau de saturação, fazendo com que os picos das curvas de compactação se aproximem expressivamente da curva de compactação alcançada no ensaio Mini-MCV, o que não acontece com as areias e siltes que não apresentam coesão alguma ou pouquíssima coesão.

\subsubsection{COEFICIENTE e'}

A classificação dos solos lateríticos e saprolíticos de acordo com a Metodologia MCT é obtida após estabelecidos todos os parâmetros classificatórios obtidos nos ensaios até então descritos, através do ábaco classificatório apresentado abaixo na Figura 3. O coeficiente e' é calculado a partir do coeficiente d'.

Segundo Nogami e Villibor (1995), esse índice, indica se o solo é laterítico ou não. Os autores relatam que se o d' $>20$ e $\mathrm{Pi}<100$, são indícios de que o solo seja laterírico. O que origina a linha horizontal principal correspondente a $e^{\prime}=1,15$ (linha tracejada 
no ábaco abaixo) que separa os solos "L" dos solos "N". Já com os solos com a porcentagem de finos muito baixa, a mudança ocorre para valores mais altos de $\mathrm{Pi}$, por esse motivo foi estabelecida a elevação da linha horizontal secundária em posição pouco acima, adequada a e' $=1,4$.

Figura 3: Ábaco: Classificação MCT

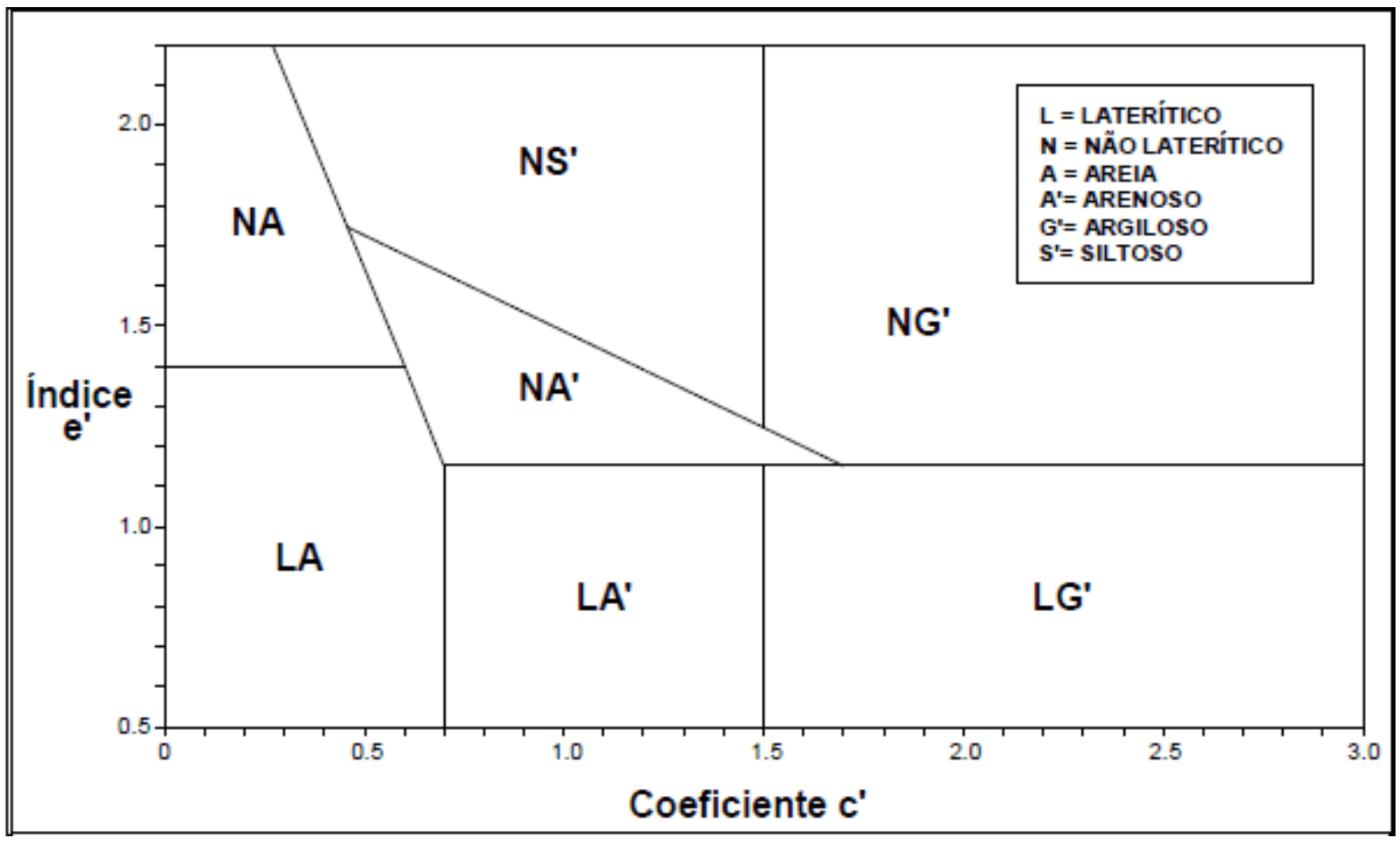

Fonte: Nogami e Villibor, (1981)

\subsubsection{ENSAIOS DA METODOLOGIA MCT}

\subsubsection{COLETA}

A coleta das amostras a serem ensaiadas foi realizada como está definido em normas regulamentadoras, assim foi seguido o passo a passo na realização dos ensaios em laboratório. Desde a coleta, transporte, recepção desse material em laboratório à execução dos ensaios todo o procedimento foi realizado de forma condizente às normatizações. 
Quando em campo, na área a ser realizada a coleta, é feita uma limpeza do material orgânico encontrado, bem como a retirada da camada superficial. Dá-se início à escavação, procurando uma camada mais bem definida para coleta. É de fundamental importância que seja registrada toda informação possível, como coordenadas, km de referência, fotografias (onde pode-se observar as características visuais do material), etc. (DNER-PRO 003-94).

\subsubsection{PREPARAÇÃO DAS AMOSTRAS}

$\mathrm{Na}$ chegada da amostra do material em laboratório, iniciou-se a preparação da mesma. Onde foi levado a um local separado, feito seu quarteamento e depois exposta em temperatura ambiente (ao sol ou estufa) prestando atenção para que essa temperatura não excedesse os $60^{\circ} \mathrm{C}$. (DNER-ME 258/94 p.04/14).

Após esse procedimento, inicia-se o outro passo que é a separação de fração dessa amostra, onde a mesma é passada na peneira de $2 \mathrm{~mm}$, destorroando a fração retida e repetindo esse procedimento quanto necessário para que passe na peneira. (DNERME 258/94).

Feito isso, retira-se uma cápsula desse material, é pesada essa amostra e leva à estufa, para análise de teor de umidade higroscópica presente no mesmo. São pesadas amostras de $500 \mathrm{~g}$ (5 porções) e acrescidas nestas umidades variantes de $1,5 \%$ a $4 \%$ a depender do tipo do material. É feita a homogeneização dessas porções com as umidades acrescentadas nas mesmas, ambas, deixadas em repouso em sacos de polietileno ou plásticos (reservados em local tampado), onde ficarão sob condição de repouso por 24 horas (DNER-ME 258/94).

Ressalta-se, que esse método de preparação da amostra servirá tanto para os ensaios Mini-MCV, Perda de massa por imersão e o Mini-CBR (com método de compactação descrito na norma rodoviária DNER-ME 228/94). 


\subsubsection{ENSAIO DE COMPACTAÇÃO MINI-MCV}

Neste ensaio tem-se a utilização do procedimento de compactação. A medida que é compactado o corpo de prova, por medição torna-se conhecida a altura final do corpo de prova após uma série de golpes aplicados. A massa volumar do corpo de prova apresenta sua linha de tendência a um valor adjunto da condição de saturação. $O$ estado de compactação atingido pela amostra é em função da umidade presente no material e o número de golpes aplicado.

Como parâmetros iniciais desse ensaio, para o Mini-MCV deve ser preparado 5 amostras de solos variando suas umidades. Dar início pela amostra que se encontra com a menor umidade, deve-se ter como referencial amostras de mesma massa (200 g) no cilindro no qual sofrerá a compactação pelo qual o ensaio é constituído, sub miniatura, sobrepondo, para cada teor de umidade, energias uniformizadas crescentes, até o alcance da densidade máxima. Após a efetivação dos cálculos, traça-se uma ascendência de curvas em gráfico, representando, para cada teor de umidade de compactação, a altura atingida de cada corpo de prova representada em milímetros no eixo das ordenadas. No eixo das abscissas, o número dos golpes do soquete compactador, bem como o traçado das curvas de deformabilidade do material. Também pra efeito de elaboração dos gráficos mostrados posteriormente. (VILLIBOR et. al, 2007).

\subsubsection{ENSAIO DE PERDA DE MASSA POR IMERSÃO (PI)}

Denota a capacidade de permanência estável do solo perante à ação da água. Compacta-se os corpos de prova, utiliza-se o extrator contido no aparelho de maneira que da superfície que esteve em contato com o soquete de compactação seja extraído $10 \mathrm{~mm}$ para fora do cilindro, de forma que seu deslocamento seja suave e contínuo para não haver estresse no $\mathrm{CP}$, o que poderia alterar quanto à sua estabilidade.

Logo, quando acomodados os CPs no tanque, deve-se encher o mesmo de maneira que a água seja liberada aos poucos com baixo nível de pressão em sua vazão. Após 20 horas no mínimo, os mesmos são retirados, de forma que as massas desprendidas 
e retidas nas cápsulas sejam levadas a estufa para secagem, tendo antes retirado excesso de água presente nelas. Com 24 horas de secagem em estufa de 100 a $105^{\circ} \mathrm{C}$, pesa-se a massa seca para cálculos de porcentagem de perda de massa por imersão, sempre levando em consideração a porcentagem de umidade presente no material.

Geralmente as argilas lateríticas, areias argilosas e argilas arenosas não se desprendem. Há perdas de pelo ao menos $100 \%$ das argilas expansivas, e areias argilosas com argilas expansivas. Areias finas e de ruim graduação bem como siltes de elevada expansão, atingem valores aproximados de $300 \%$ de perda, segundo Ferreira (1992).

O valor de PI juntamente com outros resultados da sistemática MCT, permite uma análise ampla dos comportamentos dos solos. Quando de comportamento laterítico a curva PI $\times$ Mini-MCV é descendente, ou seja, o parâmetro PI diminui quando o MiniMCV aumenta. No caso de argilas e argilas arenosas lateríticas, a PI próxima ao Mini$M C V=10$ é zero ou extremamente baixa. Para as areias argilosas lateríticas tendem aos mesmos resultados, entretanto, o decréscimo da PI ocorre para Mini-MCV mais alto e a condição de $\mathrm{PI}=0$ (zero) só acontece para Mini-MCV acima de 15, nesse caso, não se chegou ao mais elevado, porém pela média das alturas do corpo de prova e obedecendo a nota, leva em consideração o Mini-MCV de 15, de acordo com Nogami e Villibor (1995).

\subsubsection{ENSAIOS DE CAPACIDADE MINI CBR E EXPANSÃO}

O ensaio de mini CBR é incorporado aos ensaios de expansão e de contração, seus resultados fornecem os dados que dão base ao dimensionamento de pavimentos $\mathrm{e}$ correlacionam os solos que tornam o subleito reforçado como solicitado, de igual modo sub-bases, bases e acostamentos. Opta-se pela realização do ensaio com e sem imersão e sobrecarga. A depender do objetivo do estudo para utilização do solo, aplica-se energia de compactação normal e intermediária, no qual diferenciam pelo número de golpes aplicados por soquetes bem com o peso dos mesmos. 


\subsubsection{SOLOS LATERÍTICOS E SUAS PROPRIEDADES MECÂNICAS COMO COMPLEMENTO NO USO EM PAVIMENTAÇÃO}

Conforme citado anteriormente sobre a riqueza de minerais presentes nos solos lateríticos, ressalta-se os benefícios desses minerais que permitem que sejam atribuídos ao solo diversas propriedades mecânicas. Se casado com a BGS (Brita Graduada Simples), por exemplo, que são utilizadas no método convencional de execução de pavimentos até então, por serem enaltecidas pelo bom equilíbrio e resistência. O uso desse agregado, gera um custo elevado para execução dos pavimentos, neste caso, pode-se levar em consideração a redução da porcentagem do uso da BGS, complementando com o uso dos Solos Lateríticos.

Resultaria em um complemento de materiais de boa qualidade e atendimento a demanda que nesse caso é a oposição à solicitação dos esforços exercidos pelo tráfego de veículos e atingindo a economia na execução.

Conforme Nogami e Villibor (2009), das garantias, propriedades e principais peculiaridades no comportamento dos pavimentos já executados em São Paulo, descritas no livro Pavimentos Econômicos dos autores, pode-se citar: ausência de ruptura da base; pequena deflexão; contribuição estrutural da base; valor absoluto (módulo) de resiliência; recalques; trincas de reflexão e por fim recuperação.

\subsection{MÓDULO DE RESILIÊNCIA DE SOLOS E BRITAS}

A análise teórica da umidade de estabilização do subleito é o valor médio da gama de variações do teor de umidade do solo do subleito ao longo do ano especialmente em países de clima tropical como o Brasil, de acordo com Medina e Motta (2015). Esses autores citam que diante do clima tropical do país, há uma vasta gama de variação de umidades após os primeiros meses de uma execução de um pavimento. Após vários estudos de campo, contata-se que a umidade de equilíbrio dos pavimentos de rodovias que são projetados atendendo rigorosamente às normas de execução, drenadas de forma correta, em superficialidade e profundidade, se iguala, no máximo, 
ao teor de umidade do ensaio de Proctor normal de compactação. No que decorre também às camadas de base e sub-base.

Medina e Motta (2015) citam os solos mais utilizados em pavimentação no país, levando em consideração à vivencia prática da engenharia, que são: solos residuais ou saprolíticos grossos, solos lateríticos, cascalhos lateríticos, areias e pedregulhos aluvionares de rios e depósitos marginais, terraços, etc. Fortemente utilizadas as britas graduadas e solo-brita. Os macadames secos ou hidráulicos ainda são usuais em alguns estados, o que não se pode deixar de mencionar que por sua dimensão e forma construtiva não permitem serem ensaiados em laboratório. Para leitura e obtenção de seus módulos de resiliência, é adotado o processo de retro análise de bacias de deflexão obtidas por viga Benkelman, que é um exemplo de um dos instrumentos de medição.

A grande presença deste solo em abrangência no país é responsável por excelentes subleitos com baixa deformabilidade elástica e plástica dos pavimentos até então executados. Embora sem uma análise e estudos específicos voltados ao uso do mesmo como elemento âncora em uma camada executada, por exemplo. Aliado ao balanço hídrico favorável que esse solo possui, faz com que não sejam comuns afundamentos de trilha de roda como causa de ruptura nos pavimentos brasileiros (MEDINA e MOTTA, 2015)

\subsection{ESTABILIZAÇÃO DE SOLOS PARA USO EM BASE E SUB-BASE DE PAVIMENTAÇÃO}

Os materiais granulares e solos trabalham em conjunto resistindo aos esforços compressivos. Solos com fragmentos predominantemente finos são mais coesos, porém não resistem muito bem aos esforços de tração. Materiais adicionados ao asfalto são trabalhados de forma que o ligante asfáltico cause união entre suas partículas e isso aumenta gradativamente a sua resistência à compressão e à tração relacionada ao material originado (ANDRADE, 1998) 
Segundo Andrade (1998) os materiais acoplados ao cimento ou quimicamente estabilizados que recebem além da adição de cimento a cal, ou demais estabilizantes, aumentam de forma expressiva a coesão e rigidez se comparado à sua origem. Aumentando também a sua resistência à compressão e à tração. As camadas estabilizadas granulometricamente são de materiais formados por solo, mistura de variantes tipos de solos, mistura dos mesmos e materiais pedregulhosos ou produtos derivados da britagem atendendo às faixas granulométricas determinadas e demais parâmetros indicados nas especificações.

Nos pavimentos flexíveis essa estabilização dá-se com o uso do solo Estabilizado granulometricamente, brita graduada simples, brita corrida, solo brita ou solo arenoso fino laterítico e estabilizantes químicos, como o Dynabase, cal, dentre outros. Essas técnicas versam em alterar as propriedades do sistema solo-água-ar com a intenção de se obter propriedades de longa duração combinadas com uma aplicação particular (FRANÇA, 2003).

\section{PROCEDIMENTOS METODOLÓGICOS}

Diante do exposto, essa pesquisa foi desenvolvida de forma quali-quantitativas, com a realização de uma breve fundamentação teórica e em seguida a realização de ensaios em laboratório de metodologia específica com utilização de Miniaturas Compactadas Tropicais (de Solos lateríticos).

Após a realização da fundamentação teórica, fez-se o mapeamento prévio dos pontos de coleta de possíveis jazidas. Foram coletadas amostras em todos esses pontos, inclusive em alguns estimados como não lateríticos, com o intuito de obter resultados comparativos. Dentre os ensaios realizados neste, para completa análise de classificação de solos tropicais, tem-se o Mini-Proctor (compactação em miniatura), Mini-MCV, Perda de Massa por Imersão, Mini-CBR e Expansão.

Os dados obtidos e apresentados como resultados deste trabalho são de apenas um dos pontos de coleta. Este, bem como os demais, pertence à faixa de domínio de área concessionada pela VIABAHIA Concessionária de Rodovias S.A. Coletado no dia 28 
de outubro de 2019, neste mesmo dia de coleta foi dado início aos procedimentos dos ensaios. A jazida situada em meados do Km 832+375, sentido norte da BR-116, onde foi construído o acesso ao aeroporto Glauber Rocha no município de Vitória da Conquista - BA.

Durante todo estudo, foram ensaiados vários perfis de solos, de maneira tátil e visual (coloração, profundidade, localização, aspecto granulométrico, relevo, umidade, etc.). O material com resultados apresentados a seguir foi utilizado como substituição do solo existente (impróprio para uso da execução) no local da obra, nas camadas de aterro da pavimentação do acesso ao aeroporto acima mencionado.

\section{RESULTADOS E DISCUSSÕES}

Tem-se, na Figura 4, o laboratório onde foram realizados todos os ensaios descritos neste trabalho:

Figura 4: Laboratório de pesquisa, metodologia MCT

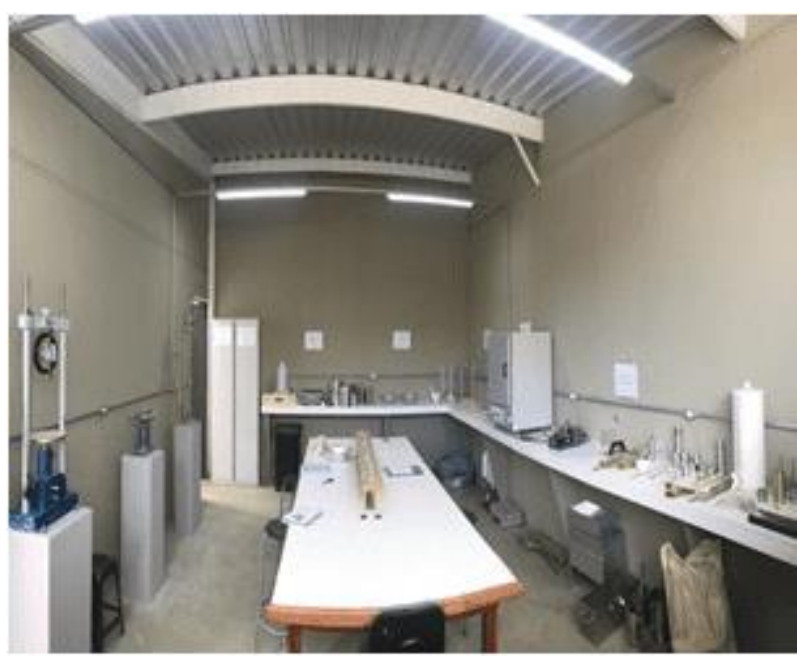

Fonte: Elaborada pelos autores 


\subsection{COLETA DAS AMOSTRAS}

Aqui, relembra-se a importância de se escolher o local adequado da coleta como em ponto sem erosões, onde nota-se a presença de materiais com mais firmeza, em taludes ou nos locais mais planos, como mostra a Figura 5.

Figura 5: Coleta de amostra

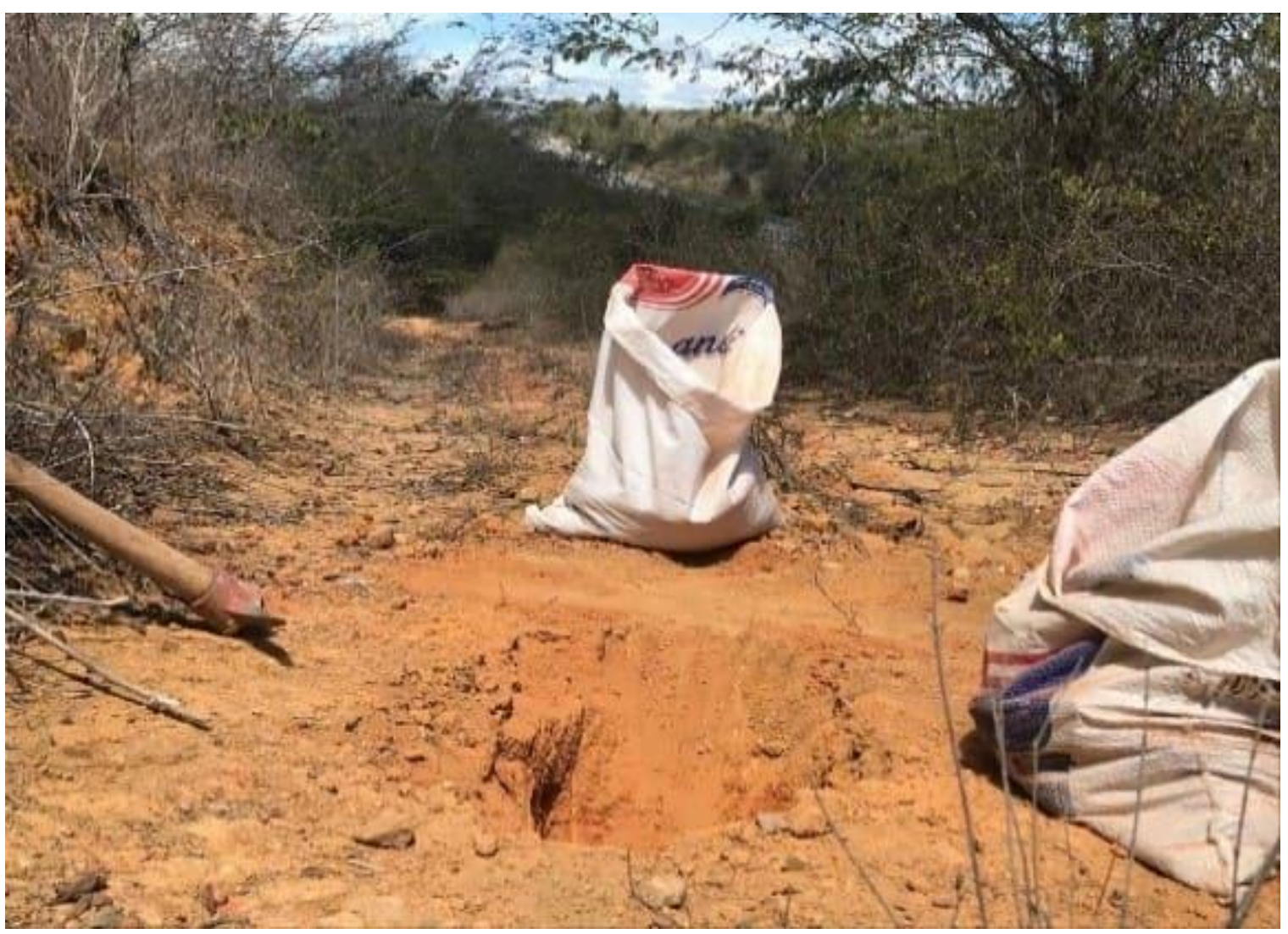

Fonte: Elaborada pelos autores 


\subsection{PREPARAÇÃO DAS AMOSTRAS}

Figura 6: Quarteamento de amostra

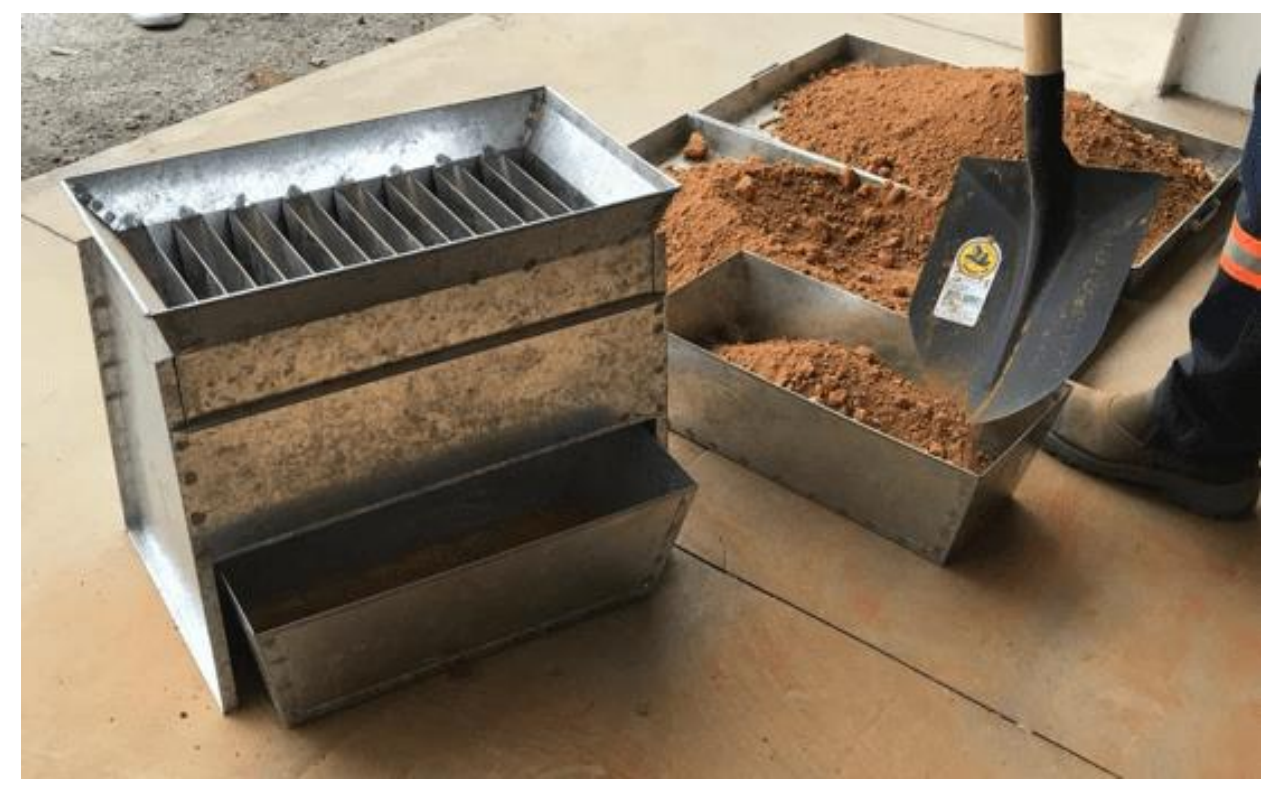

Fonte: Elaborada pelos autores

Figura 7: Secagem de cápsula da amostra em estufa para determinação da umidade higroscópica

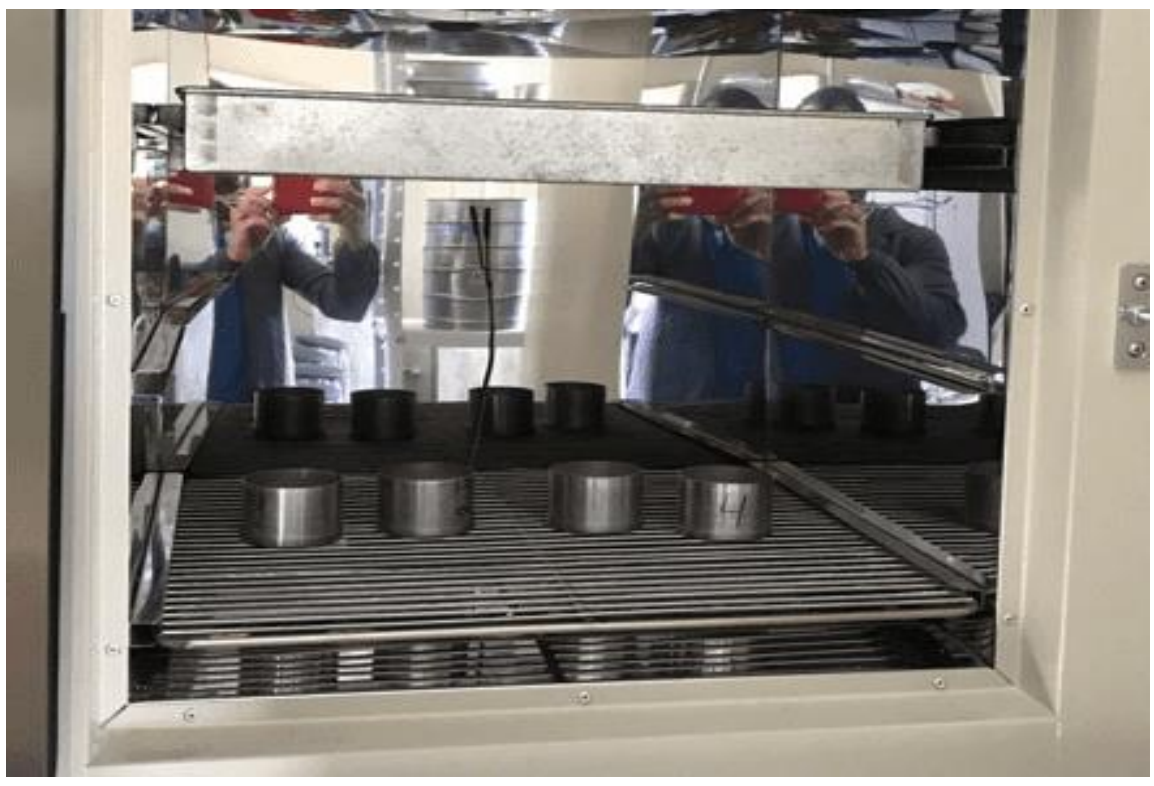

Fonte: Elaborada pelos autores

RC: 51749

Disponível em: https://www.nucleodoconhecimento.com.br/engenharia-civil/utilizacao-de-solos 
Figura 8: Acréscimo de umidade na amostra



Fonte: Elaborada pelos autores

Figura 9: Pesagem das porções da amostra

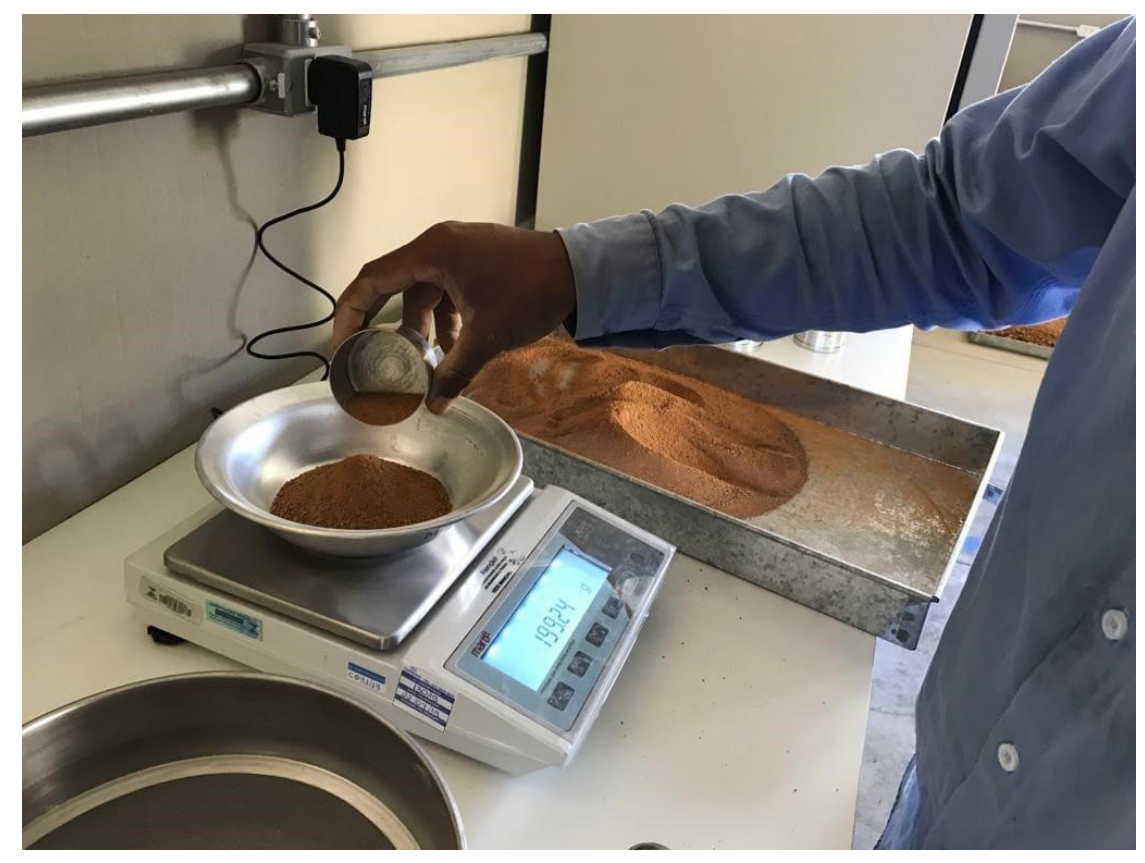

Fonte: Elaborada pelos autores 


\subsection{ENSAIOS}

\subsubsection{MINI-MCV}

Feita toda a aferição dos equipamentos, iniciou-se o ensaio conforme norma citada anteriormente. Equipamento de compactação demonstrado na Figura 10:

Figura 10: Equipamento para ensaio de compactação

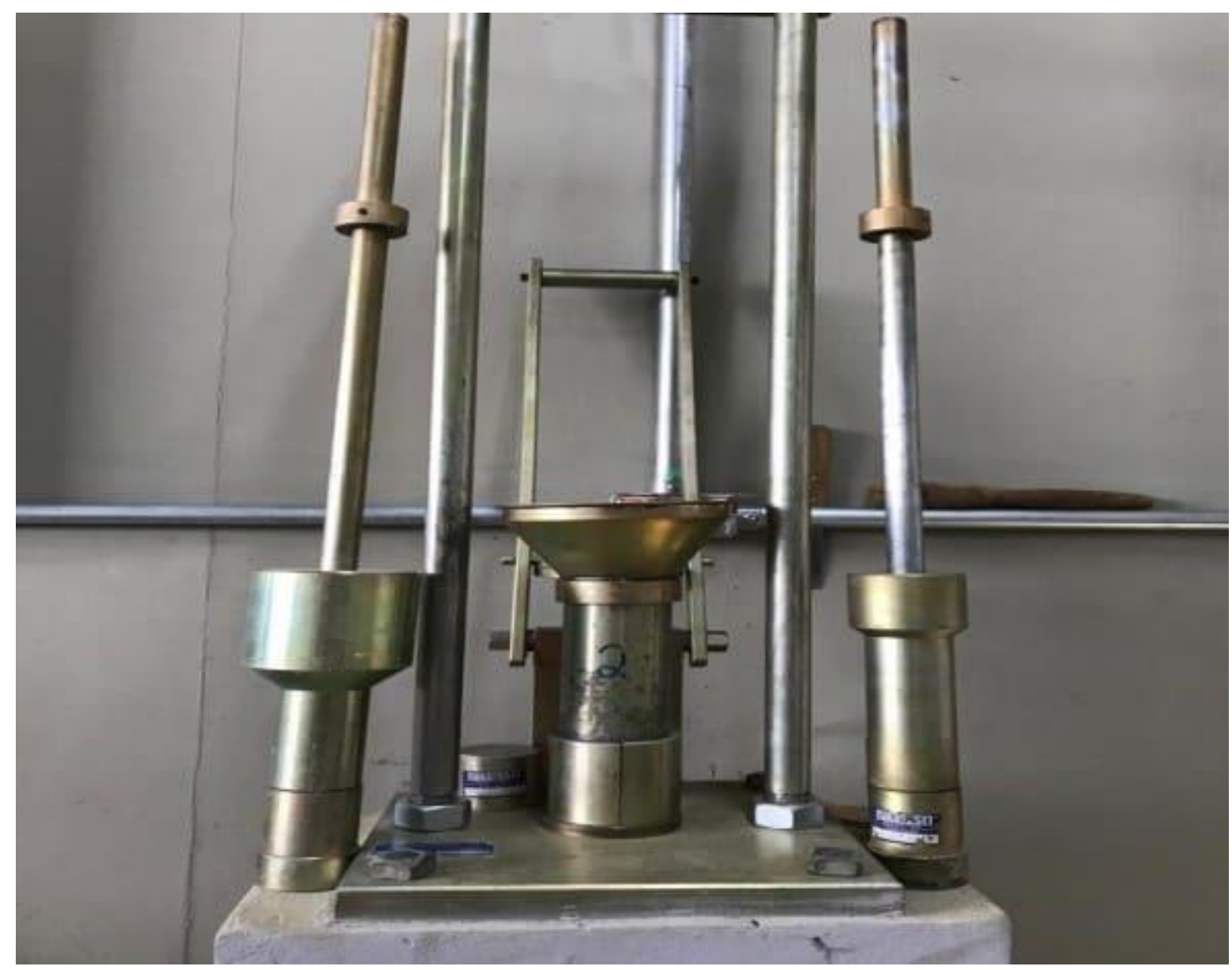

Fonte: Elaborada pelos autores

$\mathrm{Na}$ Figura 11, pode-se verificar a aplicação dos golpes com o soquete de compactação: 
Figura 11: Realização de golpes na compactação do corpo de prova



Fonte: Elaborada pelos autores

Nesta, nota-se o momento de leitura após $n$ número de golpes, utilizando um extensômetro, a leitura sendo realizada é apresentada na Figura 12.

Figura 12: Leitura de afundamento do corpo de prova

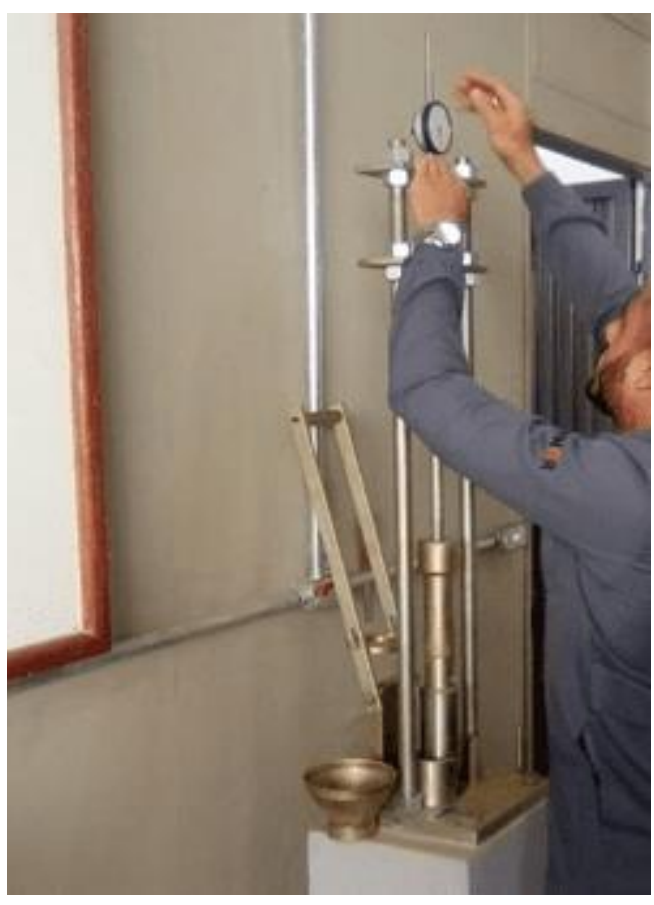

Fonte: Elaborada pelos autores

RC: 51749

Disponível em: https://www.nucleodoconhecimento.com.br/engenharia-civil/utilizacao-de-solos 


\subsubsection{MINI-CBR E EXPANSÃO}

Equipamentos utilizados e execução dos ensaios nas figuras 13 e 14 abaixo e nas Figuras 15 e 16 são apresentados os corpos de prova resultantes do ensaio:

Figura 13: Rompimento de corpo de prova para leitura do mini-CBR

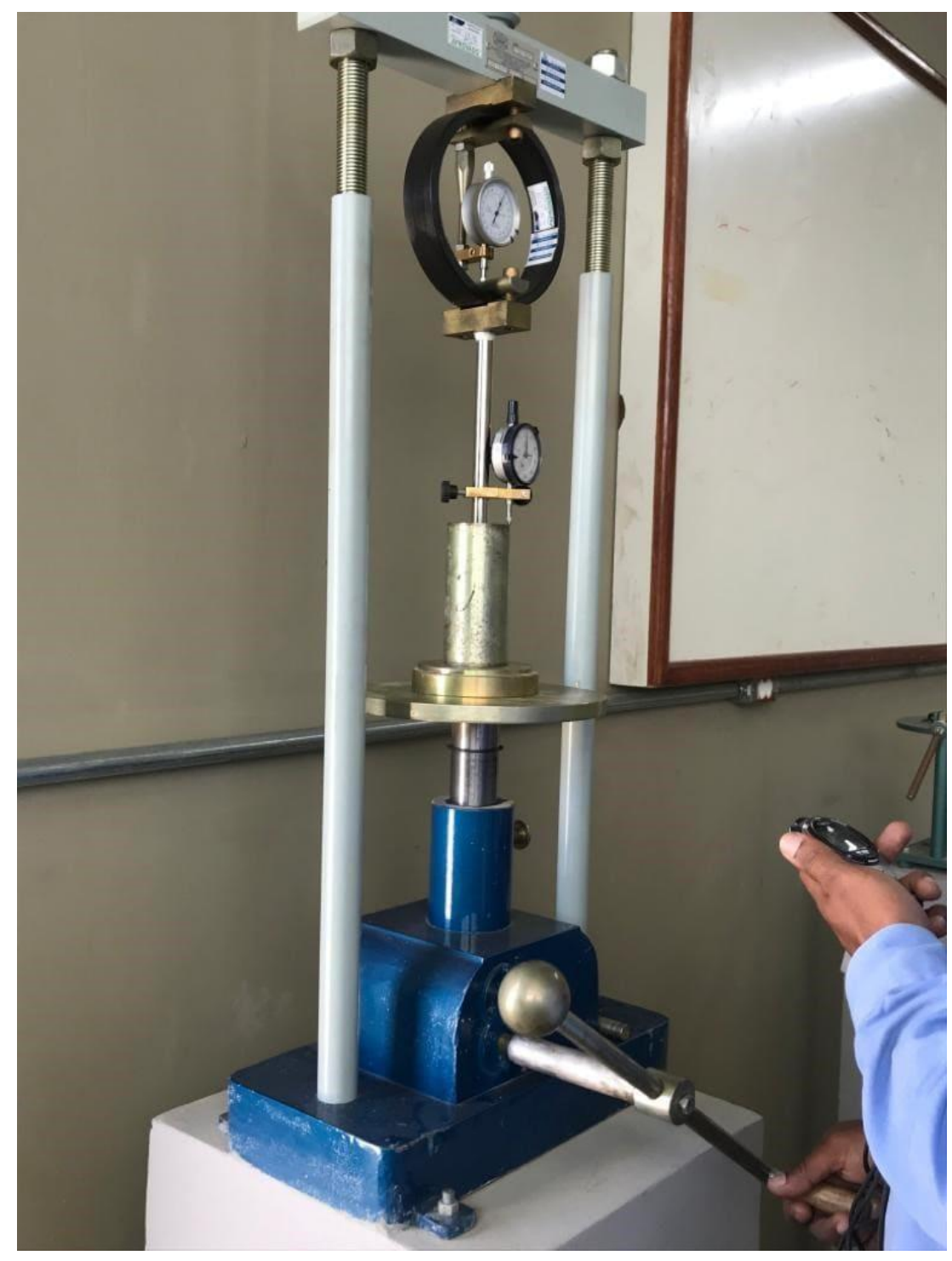

Fonte: Elaborada pelos autores 
Figura 14: Realização do ensaio de expansão

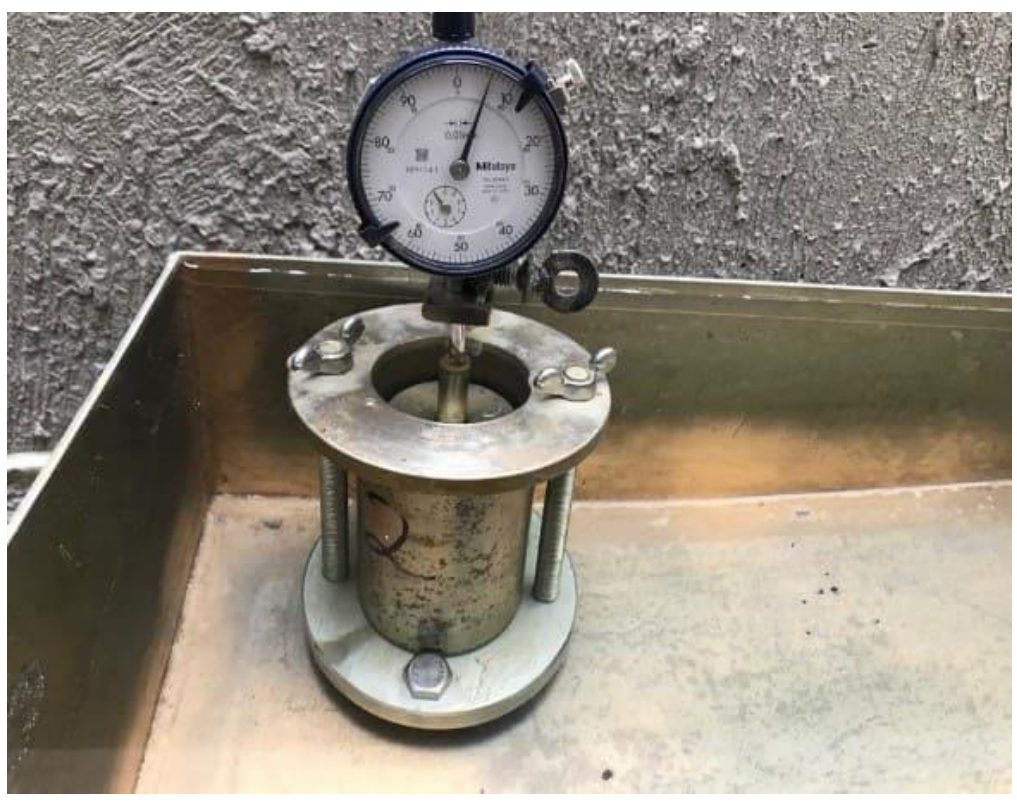

Fonte: Elaborada pelos autores

Figura 15: Demonstração do corpo de prova rompido em prensa de mini-CBR

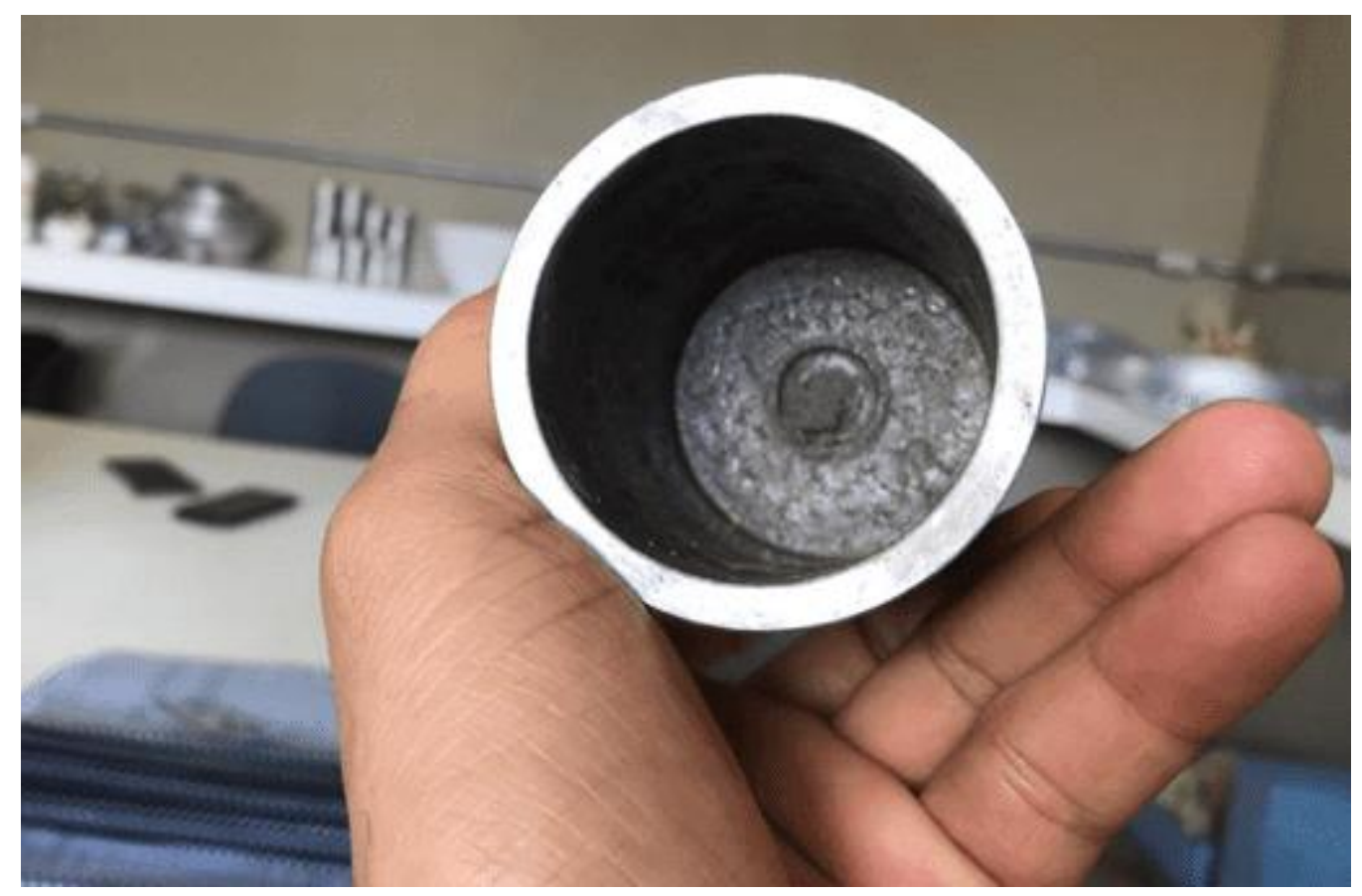

Fonte: Elaborada pelos autores 
Figura 16: Corpo de prova de extraído do cilindro após o rompimento

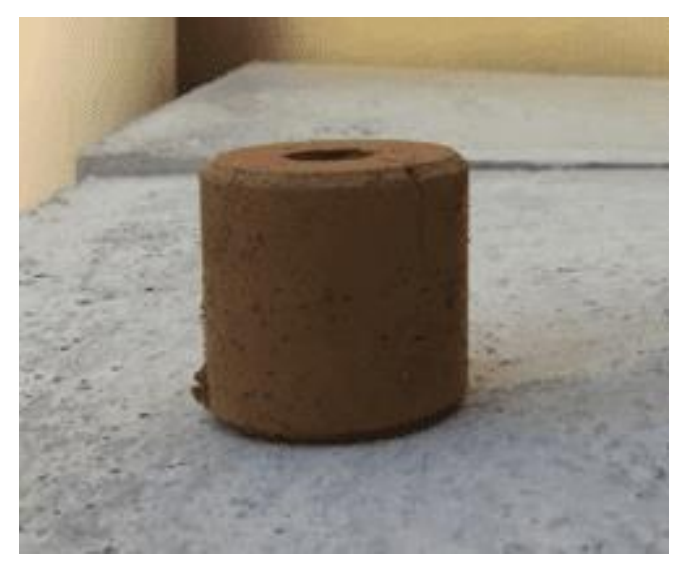

Fonte: Elaborada pelos autores

Com intuito de comparação das dimensões, a Figura 17 apresenta os corpos de prova dos ensaios de mini CBR e CBR, respectivamente da esquerda para direita.

Figura 17: Comparação entre um CP do mini-CBR e um do CBR convencional

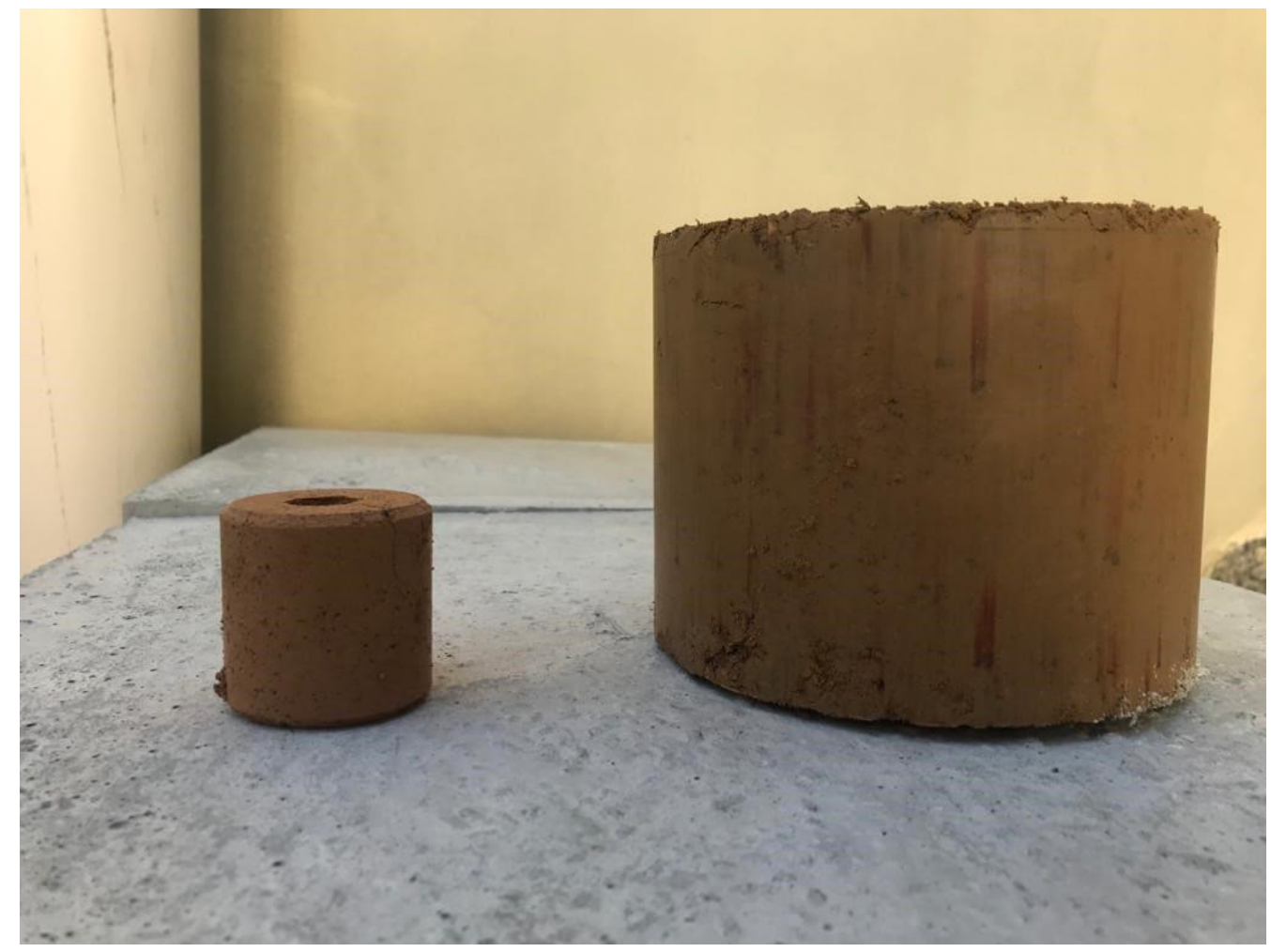

Fonte: Elaborada pelos autores 


\subsubsection{PERDA DE MASSA POR IMERSÃO (PI)}

Abaixo demonstrado na Figura 18, o momento de extração da fração do corpo de prova moldado, o qual, como mencionado anteriormente e descrito em norma rodoviária, é a base de identificação da quantidade de massa desprendida do solo em contato com a água.

Figura 18: Verificação da extração de $10 \mathrm{~mm}$ do corpo de prova para imersão em tanque



Fonte: Elaborada pelos autores

Nas figuras 19 e 20 abaixo se pode observar a etapa final do ensaio: 


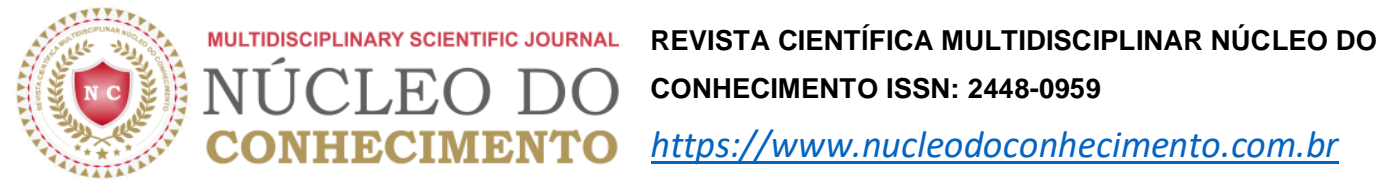

Figura 19: Demonstração de perdas de massa em corpos de provas imersos

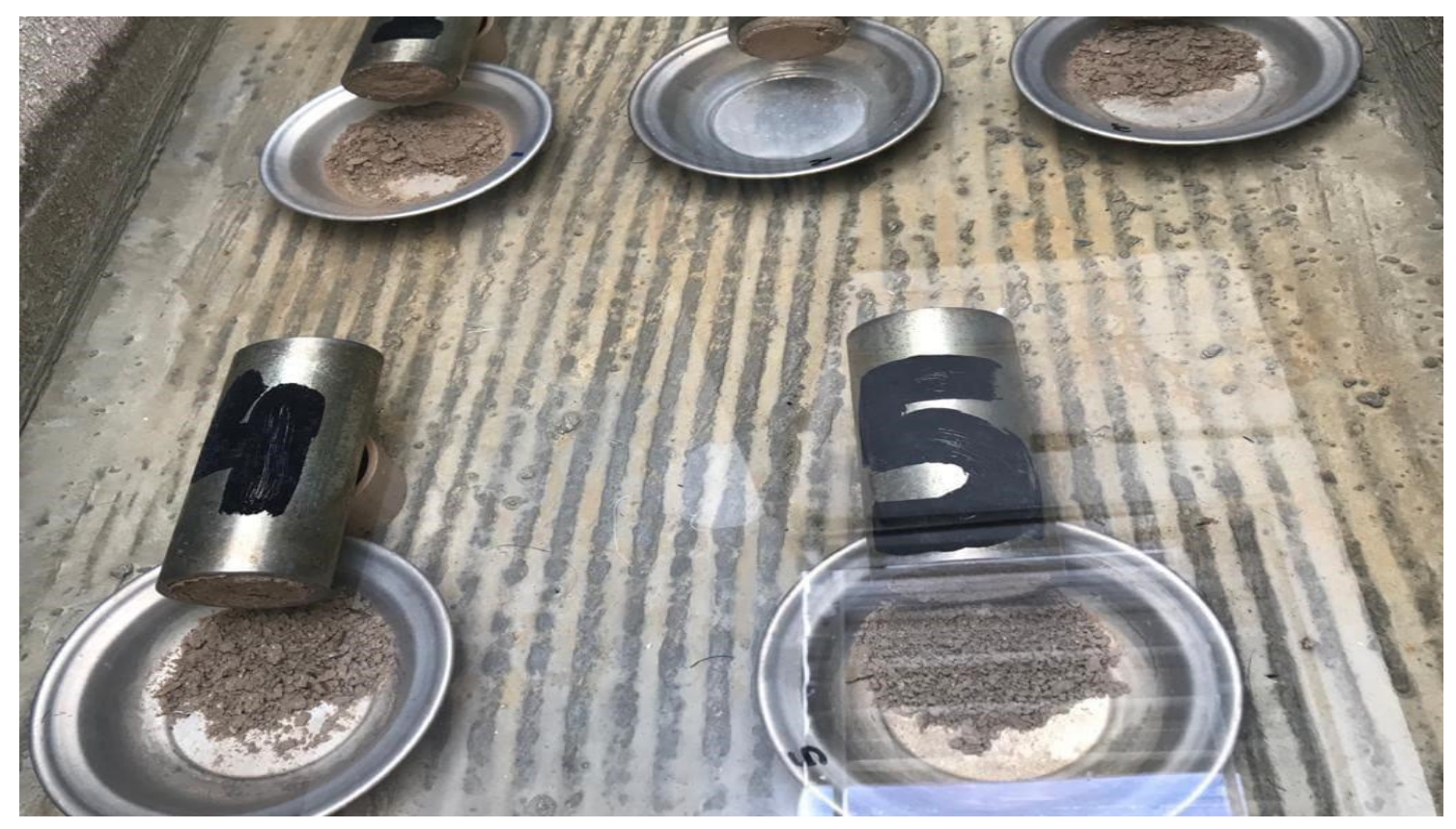

Fonte: Elaborada pelos autores

Figura 20: Massa desprendida após a secagem

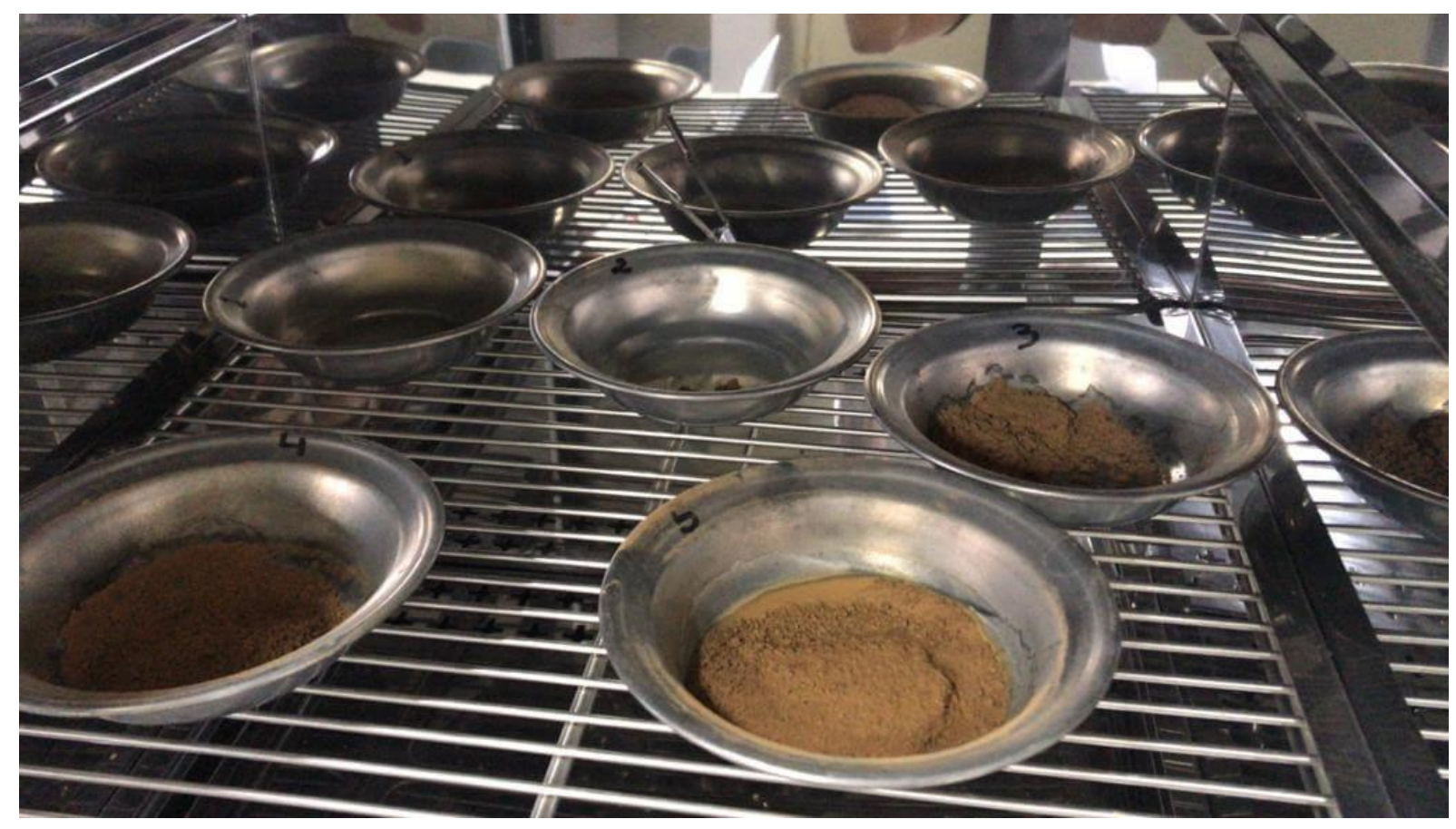

Fonte: Elaborada pelos autores

RC: 51749

Disponível em: https://www.nucleodoconhecimento.com.br/engenharia-civil/utilizacao-de-solos 


\subsection{TABULAÇÃO DE DADOS EXTRAÍDOS DOS ENSAIOS}

Para efeito de acompanhamento e entendimento de cada passo, segue-se o fluxograma com a metodologia abordada, MCT. Conforme a figura 21.

Figura 21: Programa de ensaios e dados obtidos para classificação MCT

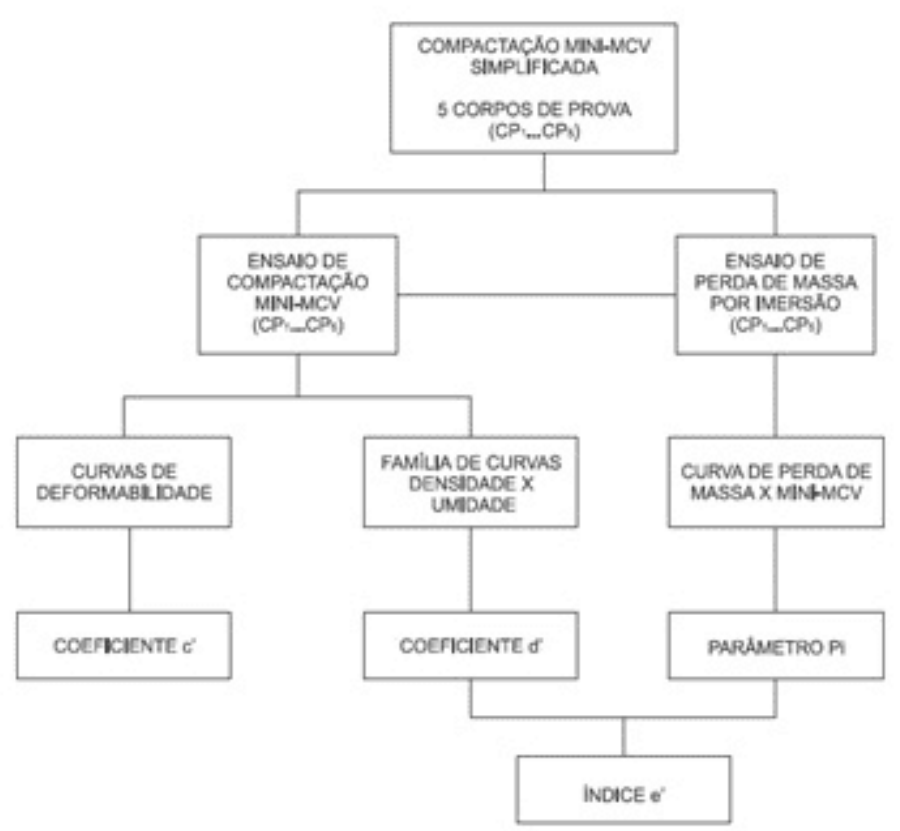

Fonte: Elaborada pelos autores

\subsubsection{RESULTADOS DOS ENSAIOS DE COMPACTAÇÃO MINI-MCV}

O valor do Mini-MCV é obtido pela expressão:

$$
(M i n i-M C V)=10 \log B n
$$

Onde:

$\log =$ algoritmo de base decimal: 
$B n=$ número de golpes que resulta da intersecção da curva Mini-MCV definida anteriormente e expressa na Figura 22, com a reta da equação $a n=2 \mathrm{~mm}$.

Para este ensaio o valor do mini-MCV, foi:

$$
(M i n i-M C V)=10 \log 5=6,99
$$

\subsubsection{CURVAS DE DEFORMABILIDADE}

O gráfico contendo as curvas de deformabilidade é apresentado na Figura 22.

Figura 22: Traçado das curvas da deformação do material

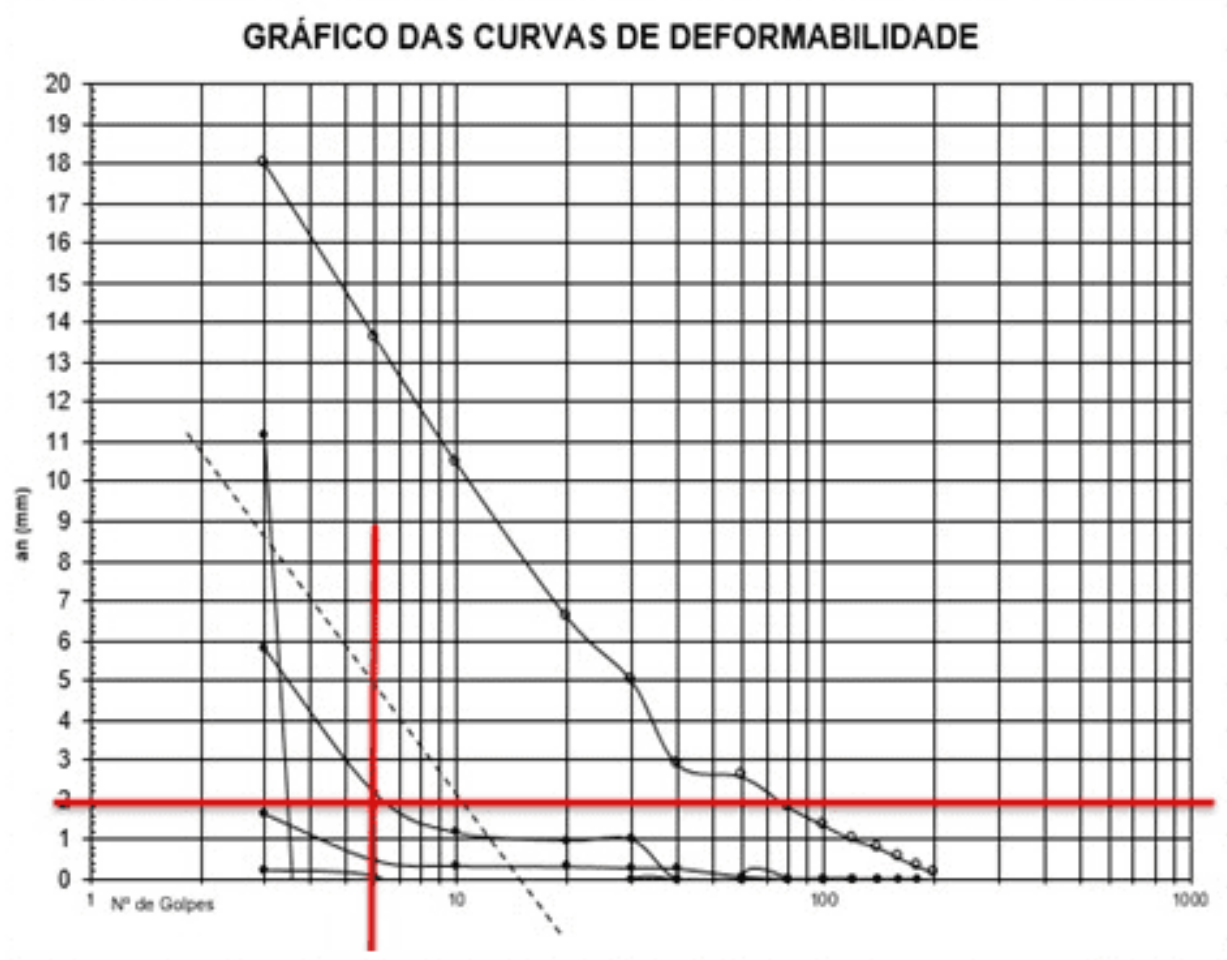

Fonte: Adaptado pelos autores, Nogami e Villibor (1995) 


\subsubsection{DETERMINAÇÃO DO COEFICIENTE c'}

O valor do coeficiente c' é obtido através daquele que foi encontrado para Mini-MCV anteriormente. É feita uma tabulação para encontrar o coeficiente de angulação da reta composta por esses valores, assim, c', neste caso, é de 0,997. A Figura 23 apresenta um resumo dos dados utilizados para a obtenção desse coeficiente.

Figura 23: Coeficiente c'

\begin{tabular}{|l|r|}
\hline \multicolumn{2}{|c|}{$C^{\prime}$} \\
\hline$Y$ & $X$ \\
\hline 5 & 10 \\
\hline 2 & 6.989700043 \\
\hline & \\
\hline 0.997 & \\
\hline
\end{tabular}

Fonte: Elaborada pelos autores

\subsubsection{FAMÍLIA DE CURVAS DENSIDADE × UMIDADE}

As Figuras 24 e 25, indicadas a seguir, contém as representações das curvas densidade $\times$ umidade e o gráfico referente à compactação realizada no ensaio de mini-MCV. 
Figura 24: Gráfico das curvas de densidade máxima e umidade ótima

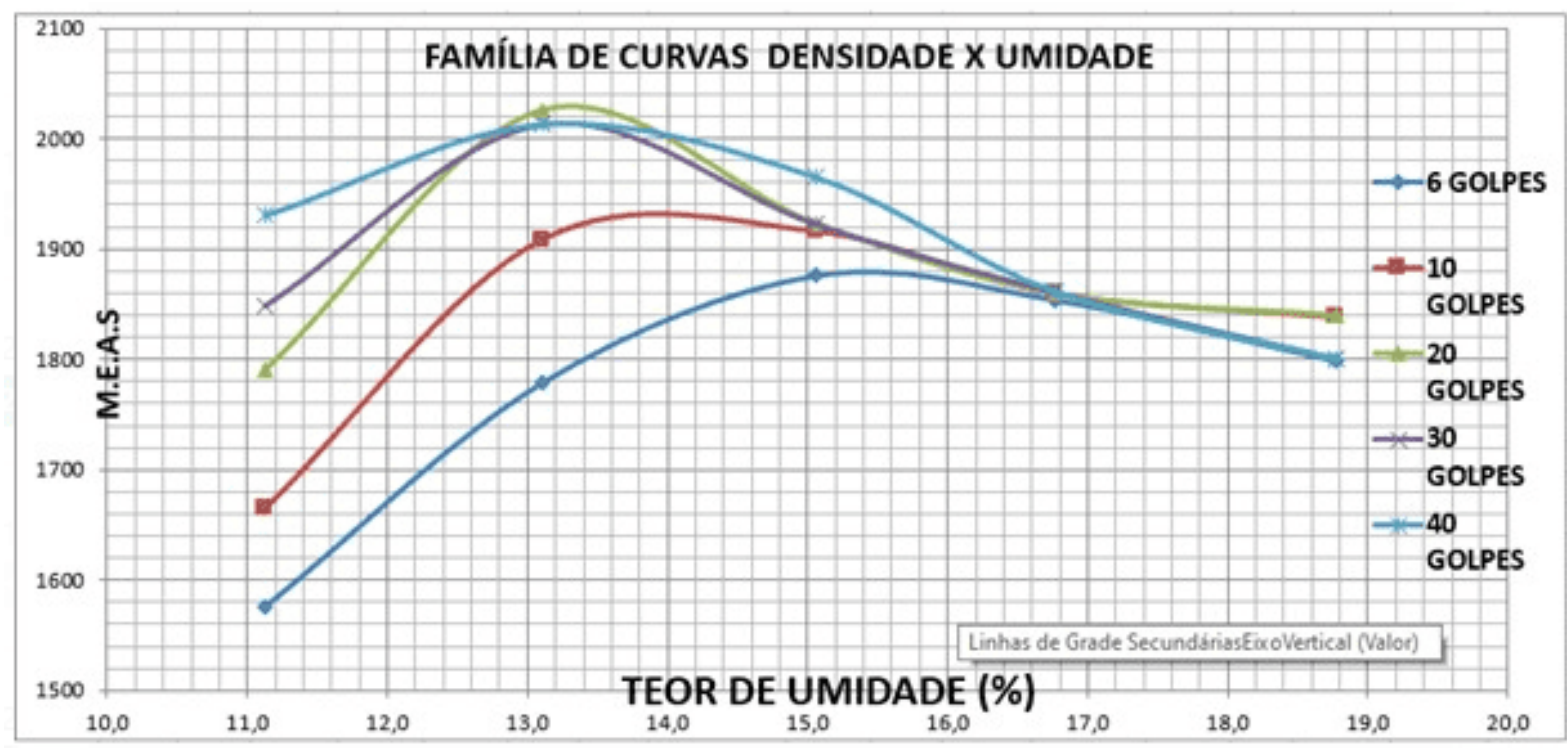

Fonte: Adaptado pelos autores, Nogami e Villibor (1995)

Figura 25: Gráfico de compactação com 10 golpes do mini-MCV

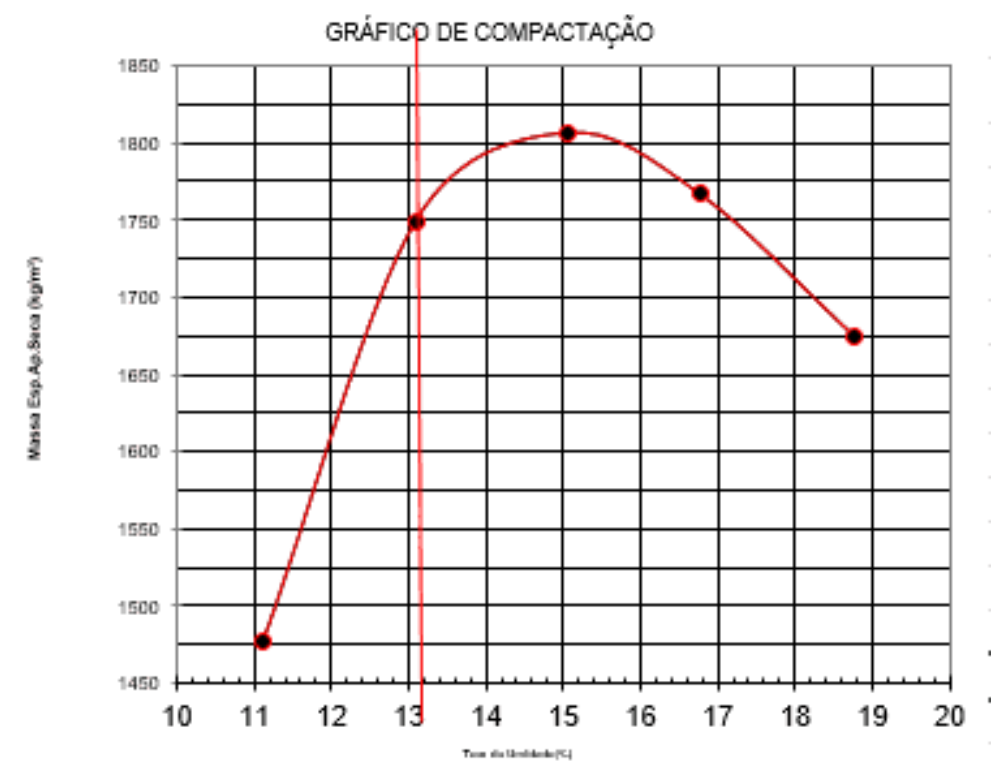

Fonte: Adaptado pelos autores, Nogami e Villibor (1995) 


\subsubsection{COEFICIENTE DO d'}

O valor referente a esse coeficiente foi obtido através da manipulação e alimentação de planilhas de dimensionamento, utilizando a inserção de dados como a densidade máxima e a umidade ótima da amostra de solo.

$$
d^{\prime}=137,1
$$

\subsubsection{RESULTADOS DO ENSAIO DE PERDA DE MASSA POR IMERSÃO}

Do material ensaiado e dos resultados extraídos, foi possível notar o bom comportamento do mesmo em relação ao contato com a umidade quando imerso, apresentando baixa porcentagem de perda de massa levando em consideração a saturação do mesmo, atendendo aos

\subsubsection{CURVA DE PERDA DE MASSA × MINI-MCV E PARÂMETROS PI}

As curvas referentes a perda de massa e ao ensaio de mini-MCV são apresentadas na Figura 26 indicada a seguir.

Figura 26: Curvas Perda de Imersão × mini-MCV

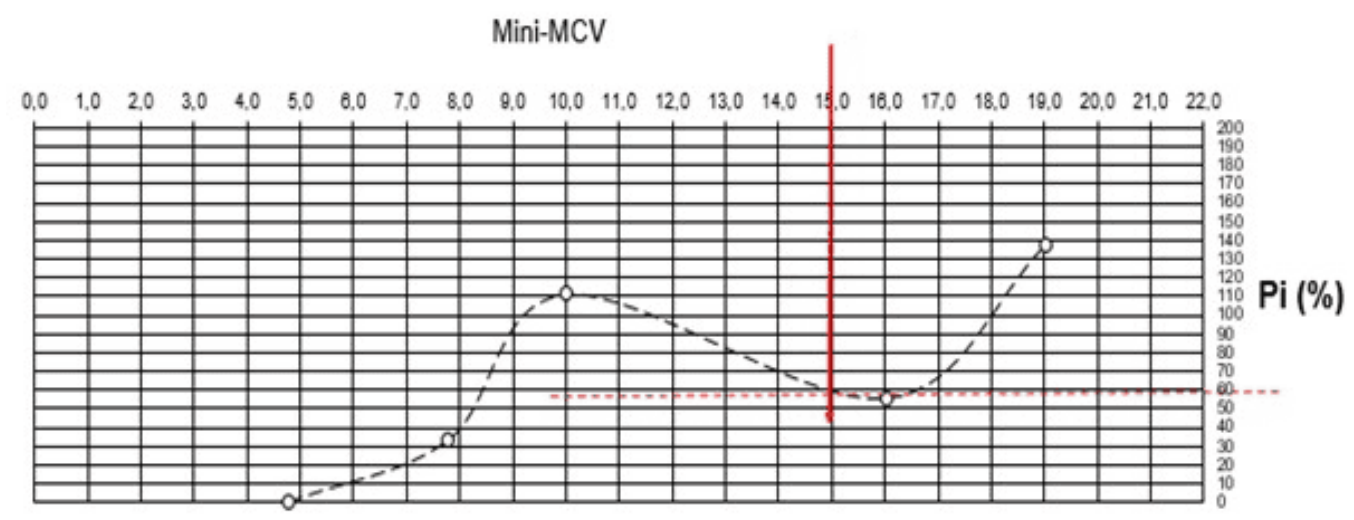

Fonte: Fonte: Adaptado pelos autores, Nogami e Villibor (1995) 
Neste, consta uma perda de massa por imersão de $60 \%$, conforme demonstrado acima.

\subsubsection{1 ÍNDICE e’}

O coeficiente e', juntamente com os outros coeficientes mencionados anteriormente, é apresentado na Figura 27 a seguir. A fórmula que define o valor de e' é:

$$
e^{\prime}=\sqrt[3]{\frac{20}{d^{\prime}}}+\frac{P i}{100}
$$

Figura 27: Valores dos coeficientes

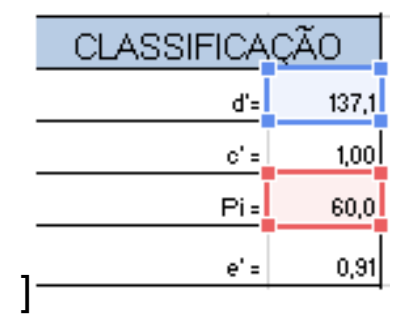

Fonte: Elaborada pelos autores

Através da obtenção dos coeficientes apresentados anteriormente foi possível identificar a amostra de solo de acordo com a subclassificação apresentada no Quadro 1. A amostra de solo em questão pôde ser classificada como LA', ou seja, um solo arenoso laterítico, como é indicado na Figura 28. 
Figura 28: Gráfico classificatório da MCT - Resultado

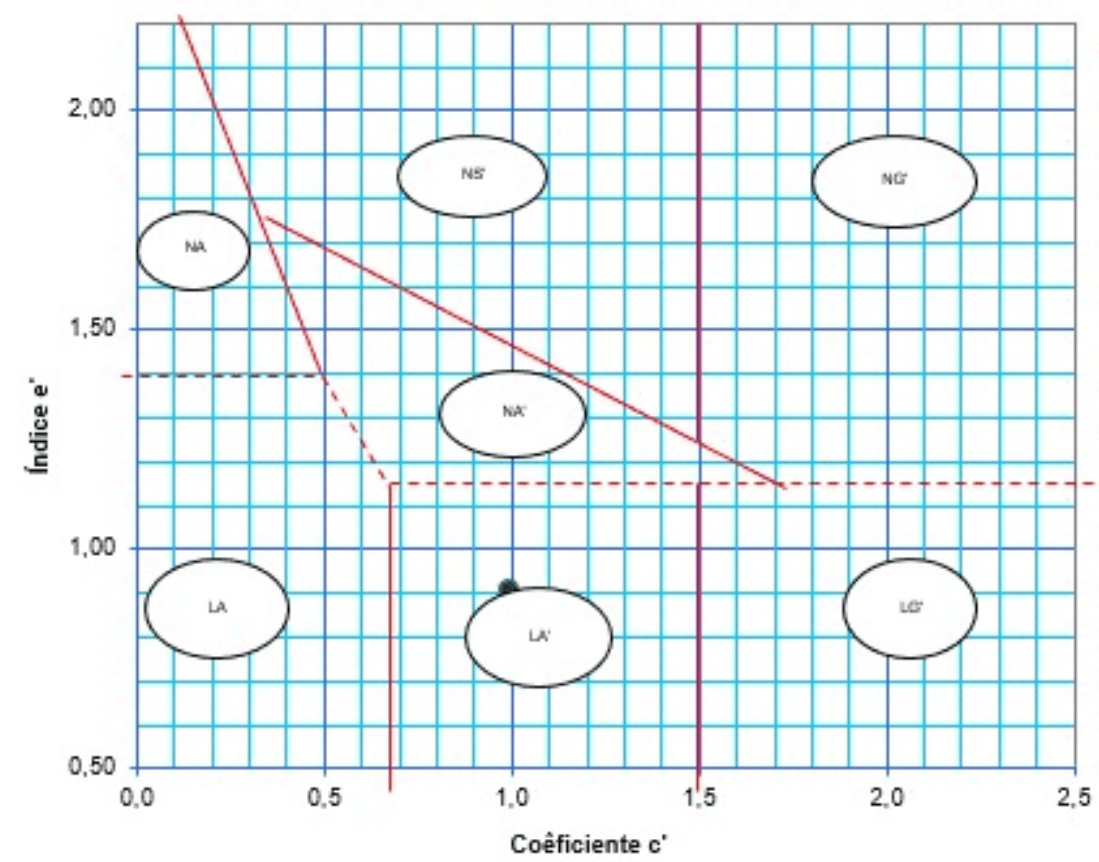

Fonte: Adaptado pelos autores, Nogami e Villibor (1995)

\section{CONSIDERAÇÕES FINAIS E DIRECIONAMENTOS FUTUROS}

Com a coleta da amostra, realização dos ensaios com uso da metodologia específica MCT para classificação de solos lateríticos, foi possível perceber que essa amostra é realmente de um solo laterítico, assim como os demais pontos mapeados e ensaiados.

A partir dos resultados obtidos em todos os ensaios realizados, tendo em vista a comprovação da existência de solos classificados como lateríticos nas áreas definidas e esperadas, ou seja, em faixas de domínio da BR-116 sob concessão da VIABAHIA Concessionária de Rodovias S.A as quais tendem a sofrer duplicações, traz-se à tona, mais uma vez conforme mencionado no corpo deste trabalho, a questão da predominância desse tipo de solo no país. Ressalta-se que a proximidade de jazidas às obras traz economia na sua execução. $E$ a execução de pavimentos econômicos com a utilização de solos lateríticos e metodologia MCT é o objetivo geral que incita todos os passos dados até então. 
Comprovado que o solo dessas áreas específicas, mencionadas anteriormente, é laterítico, passa-se agora à possibilidade de realização de ensaios utilizando estabilizantes de solos, como o Dynabase, por exemplo, dentre outros.

Esse trabalho contribui para a afirmação da importância que tem a utilização de metodologias específicas para a caracterização de solos, e assim os próximos trabalhos a serem produzidos têm o intuito de apresentar o dimensionamento e execução experimental de pavimentos, utilizando esse tipo de solo e metodologia, interligados aos métodos de dimensionamentos existentes e usuais, bem como adequação a futuros métodos, citando previamente o MeDiNa (Método de Dimensionamento nacional de Pavimentação), tendo em vista sua já aguardada aprovação e oficialização pelo DNIT (Departamento Nacional de Infraestrutura de Transportes). Esse mesmo método leva em consideração o módulo de resiliência dos materiais e não mais o seu CBR, fazendo com que o conhecimento do material utilizado, ou seja, sua classificação, propriedades e comportamento, se torne de certa forma ainda mais relevante para o dimensionamento, execução e reestruturação de rodovias.

\section{REFERÊNCIAS}

AMERICAN ASSOCIATION OF STATE HIGHWAY AND TRANSPORTATION OFFICIALS. Guide for Design of Pavement Structures. Washington, DC, 20001, 1993

ASSOCIAÇÃO BRASILEIRA DE NORMAS TÉCNICAS. NBR 6459: Solo Determinação do limite de liquidez. Rio de janeiro: ABNT, 1984

ASSOCIAÇÃO BRASILEIRA DE NORMAS TÉCNICAS. NBR 6508: Grãos de solos que passam na peneira de 4,8 mm - Determinação da massa específica. Rio de janeiro: ABNT, 1984

ASSOCIAÇÃO BRASILEIRA DE NORMAS TÉCNICAS. NBR 7180: Solo Determinação do limite de plasticidade. Rio de janeiro: ABNT, 1984 
ASSOCIAÇÃO BRASILEIRA DE NORMAS TÉCNICAS. NBR 7181: Solo - Análise granulométrica. Rio de janeiro: ABNT, 1984

ASSOCIAÇÃO BRASILEIRA DE NORMAS TÉCNICAS. NBR 7182: Solo - Ensaio de compactação. Rio de janeiro: ABNT, 1986

ASSOCIAÇÃO BRASILEIRA DE NORMAS TÉCNICAS. NBR 9895: Solo -Índice de suporte califórnia. Rio de janeiro: ABNT, 1987

BERNUCCI, L. B.; MOTTA, L. M.; CERATTI, J. A. P.; SOARES, J. B.. Pavimentação Asfáltica: Formação Básica para Engenheiros. 1. ed. Rio de Janeiro, RJ. 2006.

DNER - ME (1994). ME-256/94. Solos compactados com equipamento miniatura determinação da perda de massa por imersão. Departamento nacional de estradas de rodagens. $6 p$.

DNER - PRO (1994). PRO-003/94. Coletas de amostras deformadas de solos. Departamento nacional de estradas de rodagens. 14p.

DNER ME (1994). ME-254/97. Solos compactados em equipamento miniatura - MiniCBR e expansão. Departamento nacional de estradas de rodagens. 14p.

DNER ME (1994). ME-258/94. Solos - compactados em equipamento miniatura - MiniMCV. Departamento nacional de estradas de rodagens. 14p.

DNER ME (1994). ME-28/94. Solos - compactação em equipamento miniatura. Departamento nacional de estradas de rodagens. 14p.

DNIT (2016). Solos - Determinação de índice de suporte Califórnia utilizando amostras não trabalhadas - Método de ensaio. Publicação IPR - 172. Ministério do transporte. Departamento nacional de infraestrutura de transportes, Instituto de pesquisas rodoviárias.

DYNABASE. Estabilizante de solo. Disponível em: <https://www.dynabase.com.br/>. Acesso em: 23 set. 2019. edição.P 6-32 
ESPINDOLA, Carlos Robeto; DANIEL, Luiz Antonio. Laterita e solos lateríticos no Brasil. Disponível em: <http://webcache.googleusercontent.com/search?q=cache:tHFzvAnsc8J:bt.fatecsp.br/system/articles/724/original/004.pdf+\&cd=1\&hl=ptBR\&ct=clnk\&gl=br>. Acesso em: 05 nov. 2019.

FERREIRA, M.A.G., Características Físicas de Solos Tropicais e Comportamento nos Pavimentos. Tese de Doutorado. Universidade de São Paulo - Escola de Engenharia de São Carlos, São Carlos, 1992.

FRANÇA, Fabrício Carlos. Estabilização Química de Solos para Fins Rodoviários: Estudo de Caso com o Produto "RBI Grade 81". 104f. Dissertação (Mestrado). Universidade Federal de Viçosa, Minas Gerais, 2003.

LEPSCH, Igo F. (2010). Formação e conservação dos solos. 2. ed. São Paulo: Oficina de Textos, 2010.

LIMA, Valmiqui Costa; LIMA, Marcelo Ricardo de. O solo no meio ambiente: Abordagem para Professores do Ensino Fundamental e Médio e Alunos do Ensino Médio.

Disponível

em:

<http://webcache.googleusercontent.com/search?q=cache:MedVoznEUqMJ:www.es cola.agrarias. ufpr.br/arquivospdf/livro.pdf $+\& c d=1 \& \mathrm{hl}=\mathrm{pt}-\mathrm{BR} \& \mathrm{ct}=\mathrm{clnk} \& \mathrm{gl}=\mathrm{br}>$. Acesso em: 28 ago. 2019.

MEDINA, Jacques de; MOTTA, Laura Maria Gotetti da. Mecanica dos pavimentos. 3 ed. Rio de Janeiro: Interciência, 2015. 352 p.

NETO, José Pereira de Queiroz. Pedologia: conceito, método e aplicações. Disponível em: <http://webcache.googleusercontent.com/search?q=cache:IBwLKyQfZDUJ:www.revi stas.usp.br/rdg/article/view/47088+\&cd=1\&hl=pt-BR\&ct=clnk\&gl=br>. Acesso em: 18 ago. 2019.

SILVA, Luiz Alberto da. Estudo comparativo entre base estabilizada granulometricamente e Dynabase. Estudo de caso: rodovia MGT/ 267 - trecho 
monsenhor

Paulo/mg

a

Cordislândia/mg.

Disponível

em:

$<$ http://webcache.googleusercontent.com/search?q=cache:JwhMOtFKmqYJ:reposito rio.unis.edu.br/bitstream/prefix/252/1/LUIZ\%2520ALBERTO\%2520DA\%2520SILVA.p $d f+\& c d=2 \& h l=p t-B R \& c t=c l n k \& g l=b r>$. Acesso em: 12 ago. 2019.

SOUZA, Ricardo Andrade de. Estudo comparativo dos ensaios de CBR e MiniCBR para solos de Uberlândia-MG. Disponível em: <https://webcache.googleusercontent.com/search?q=cache:BeQ_ps6D910J:https://re positorio.ufu.br/handle/123456789/14236 $+\& \mathrm{~cd}=2 \& \mathrm{hl}=\mathrm{pt}-\mathrm{BR} \& \mathrm{ct}=\mathrm{clnk} \& \mathrm{gl}=\mathrm{br}>$. Acesso em: 10 set. 2019.

VILLIBOR, D.F. et all. Pavimentos de baixo custo para vias urbanas: bases alternativas com solos lateríticos. São Paulo: Arte \& Ciência, 2007.

VILLIBOR, Douglas Fadul; Nogami, Job Shuji. Pavimentos de baixo custo com solos lateríticos. 1. ed. São Paulo: Arte e ciência, 2009.

VILLIBOR, Douglas Fadul; Nogami, Job Shuji. Pavimentos econômicos. 1. ed. São Paulo: Arte e ciência, 1995.

WLASTERMILER DE SENÇO. Manual técnico de pavimentação 2008. Volume 1. 2.

Enviado: Maio, 2020.

Aprovado: Junho, 2020. 